\title{
Neutron and Gamma (Density) Logging in Welded Tuff
}

\author{
Wunan Lin
}

September 12, 1997

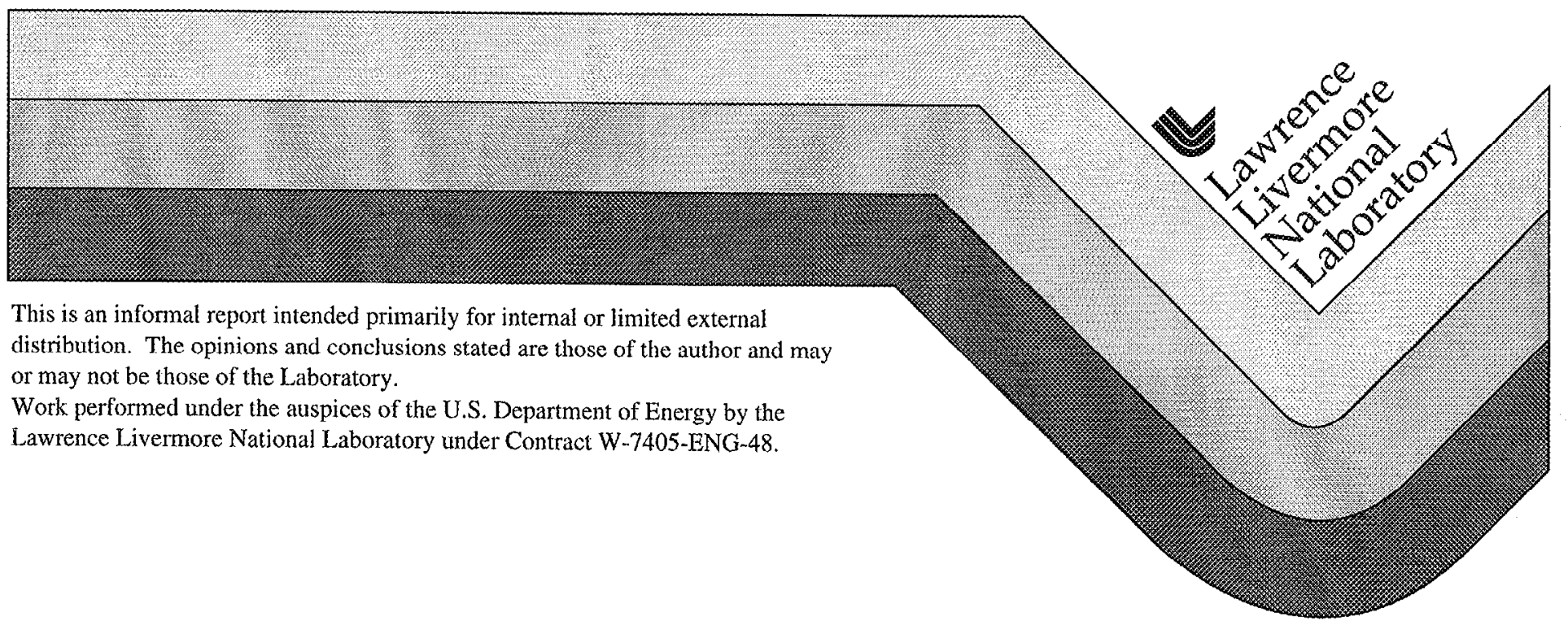




\section{DISCIAIMER}

This document was prepared as an account of work sponsored by an agency of the United States Government. Neither the United States Government nor the University of California nor any of their employees, makes any warranty, express or implied, or assumes any legal liability or responsibility for the accuracy, completeness, or usefulness of any information, apparatus, product, or process disclosed, or represents that its use would not infringe privately owned rights. Reference herein to any specific commercial product, process, or service by trade name, trademark, manufacturer, or otherwise, does not necessarily constitute or imply its endorsement, recommendation, or favoring by the United States Government or the University of California. The views and opinions of authors expressed herein do not necessarily state or reflect those of the United States Government or the University of California, and shall not be used for advertising or product endorsement purposes.

This report has been reproduced directly from the best available copy.

Available to DOE and DOE contractors from the Office of Scientific and Technical Information

P.O. Box 62, Oak Ridge, TN 37831

Prices available from (423) 576-8401

Available to the public from the National Technical Information Service

U.S. Department of Commerce 5285 Port Royal Rd. Springfield, VA 22161 


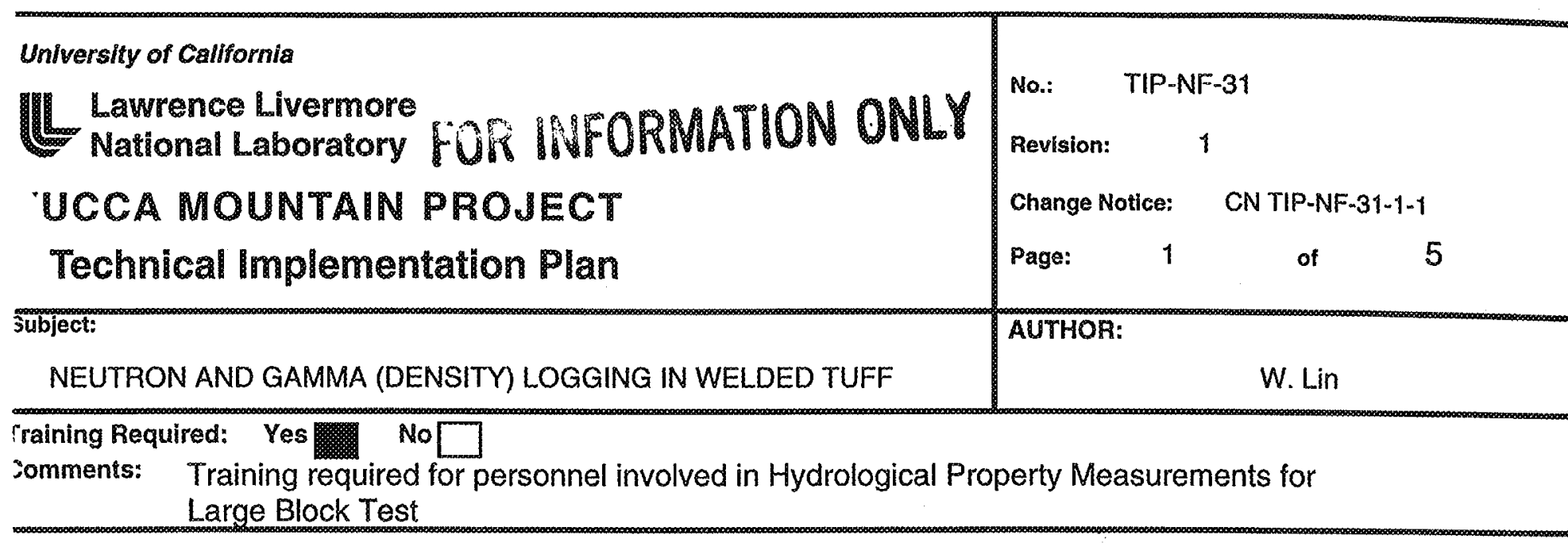

\section{REVISION HISTORY}

\begin{tabular}{|c|c|c|c|}
\hline Rev. No. & CNNo. & Effective Date & Description of Revision/CN \\
\hline 0 & & $5 / 26 / 94$ & Initial issue. \\
\hline 1 & & $7 / 12 / 94$ & $\begin{array}{l}\text { Changes to text, change in } \\
\text { section numbering. }\end{array}$ \\
\hline 1 & CN TIP-NF-31-1-1 & $9 / 12 / 97$ & $\begin{array}{l}\text { Text changes made to responsibili- } \\
\text { ties; addition of } 503 \text { DR Hydroprobe } \\
\text { Moisture Depth Gauge Operating } \\
\text { Manual as addendum. Affects Title } \\
\text { Page and pages } 2 \text { and } 3 \text { of } 5 \text {. }\end{array}$ \\
\hline
\end{tabular}

APPROVALS:

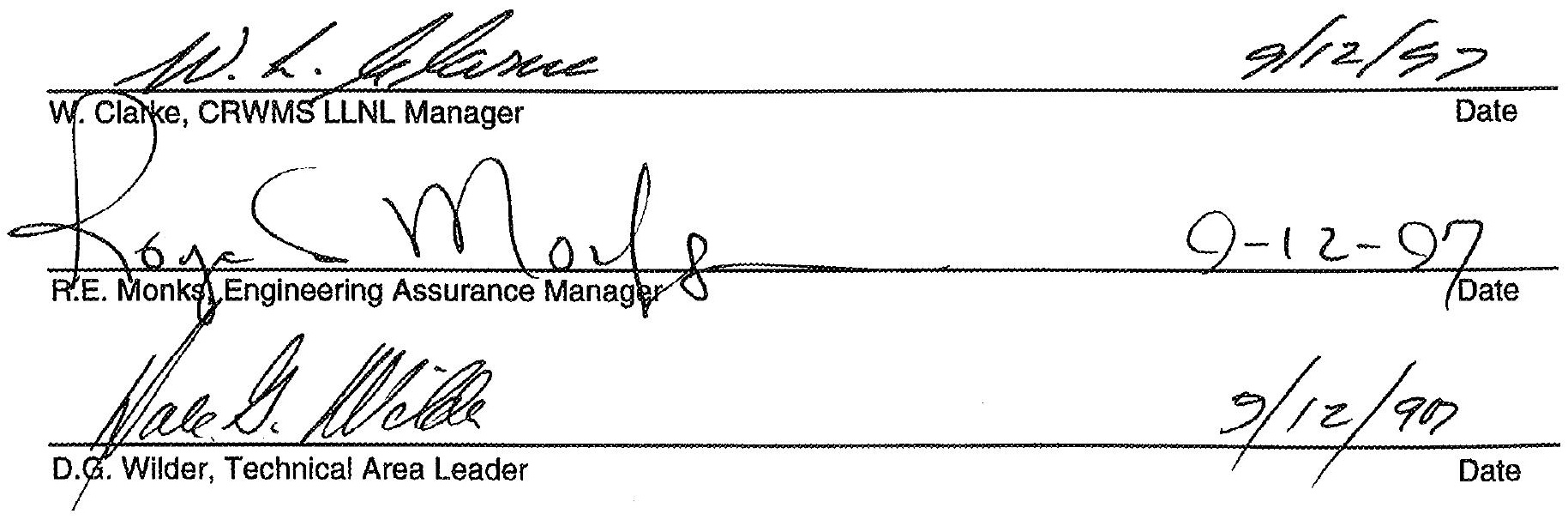





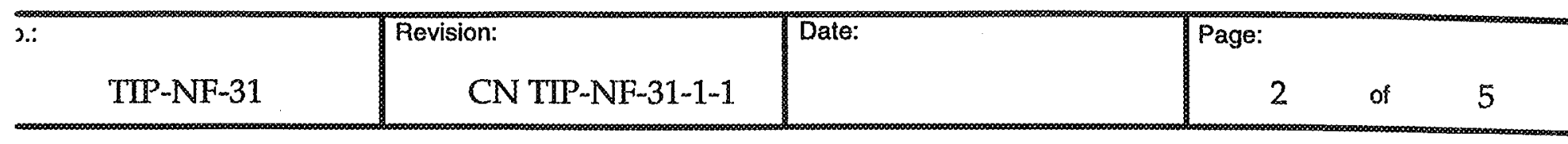

1.0 PURPOSE

This Technical Implementation Procedure (TIP) describes the field operation, and the management of data records pertaining to neutron logging and density logging in welded tuff. This procedure applies to all borehole surveys performed in support of Engineered Barrier System Field Tests (EBSFT), including the Large Block Tests (LBT) and Initial Engineered Barrier System Field Tests (IEBSFT) - WBS 1.2.3.12.4. The purpose of this TIP is to provide guidelines so that other equally trained and qualified personnel can understand how the work is performed or how to repeat the work if needed. The work will be documented by the use of Scientific Notebooks (SNs) as discussed in 033-YMP-QP 3.4. The TIP will provide a set of guidelines which the scientists will take into account in conducting the measurements. The use of this TIP does not imply that this is repetitive work that does not require professional judgment.

\section{$2.0 \quad \underline{\text { SCOPE }}$}

This TIP applies to all density logging and neutron logging for water content performed in support of EBSFT - WBS 1.2.3.12.4.

\subsection{RESPONSIBILITIES}

The Task Leader for EBSFT - WBS 1.2.3.12.4 is responsible for assuring that this procedure is used. The Task Leader is also responsible for assuring that any changes to this procedure are reviewed and incorporated in the next revision.

\subsection{DESCRIPTION OF PARTS/ASSEMBLAGE AND CHECKOUT}

The operations manual (Campbell Pacific Nuclear Corporation, 1984) for the logging tools describes all the components of the logging system used. It also describes the appropriate assemblage and checkout procedures. A copy of the operations manual will be attached to the "Field Copy" of this procedure.

\subsection{EIELDMEASUREMENTS}

The field measurement sequence includes measurements of a standard outside the boreholes and measurements within boreholes for moisture or density testing.

a) Measurement of Standard Counts: The calibration of the moisture or density system is made in terms of a ratio to standard count made with the probe secured within the shielded surface unit or a special calibration fixture. A log will be kept of the standard counts taken before and after each borehole survey, or suite of surveys (i.e., at the beginning and end of each day's surveys), to allow the user to determine when a defect occurs and the rate of change per unit time of course. Selection of an appropriate base station location is discussed in the manual of operation.

b) Borehole Logging: Instructions on how to operate the tools are described in the operations manuals. Additional operational requirements are as follows. 



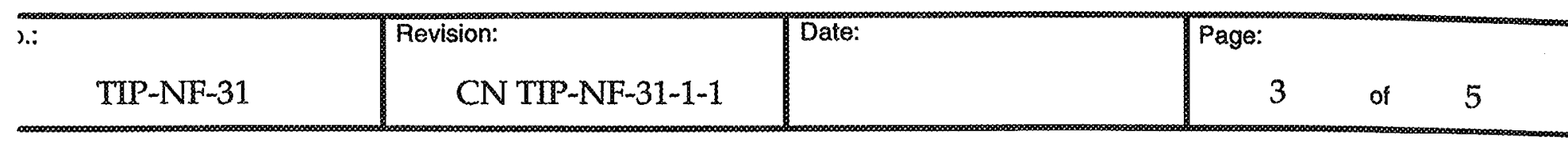

1) Counting time: The counting time at each sampling location should be at least $16 \mathrm{sec}-$ onds for the neutron measurements and at least $240 \mathrm{sec}(4 \mathrm{~min}$.) for the density measurements with the probe remaining immobile during counting.

2) Sampling Interval: The maximum sampling interval (i.e., the distance between individual sampling locations) should be smaller than the radius of investigation of the probe. The radius of the investigation of the neutron probe is a function of the water content of the rock and can be estimated using the formula supplied by the manufacturer in the operations manual. The sampling interval used will be selected such that there is an overlap in the volume of investigation of approximately $20 \%$ between consecutive sampling stations. There is no known formula to calculate the radius of investigation of the density probe. The present judgment is that it will be of the same order as that of the neutron probc.

The range of depths to be sampled in each borehole will be determined based on the results of geohydrologic scoping calculations. The range of depths to be sampled should completely include those sections of the rock mass which according to the scoping calculations will undergo detectable changes in moisture content during the experiment. At present, there is no information available regarding what is the smallest change in moisture content which can be detected with this logging system. The judgment is that a change in moisture content of a few percent of the original value may be detectable.

Thus, it is recommended that the section of the borehole to be logged include (as a minimum) those sections where changes in moisture content of $3-4 \%$ (relative to the pristine value) are expected.

The data collected during neutron and density surveys will be recorded manually in SNs. The records will identify the borehole, date and time, and persons conducting the survey data. The survey data will include the standard counts obtained before the logging run. If a number of borehole surveys are performed in one day, record the standard counts at the beginning and end of each day's surveys. The depths at which each measurement was made, neutron counts (or density), and a standard count obtained at the end of each logging run will also be recorded. The SNs will also list the times and date when the rechargeable battery pack of the unit is recharged and of any maintenance performed on the tool. SNs will be handled in accordance with procedure 033-YMP-QP 3.4.

Documentation of the methods or procedures used to perform the test/activity will be provided in the SNs and the method or approach used will be determined by the Principal Investigator or the person assigned by the Principal Investigator to do the work. As such, deviations from the suggested or typical approaches outlined in this procedure are allowed based on the technical judgment of the scientist responsible for this activity. Revised procedures will then be prepared to reflect changes, when appropriate. 



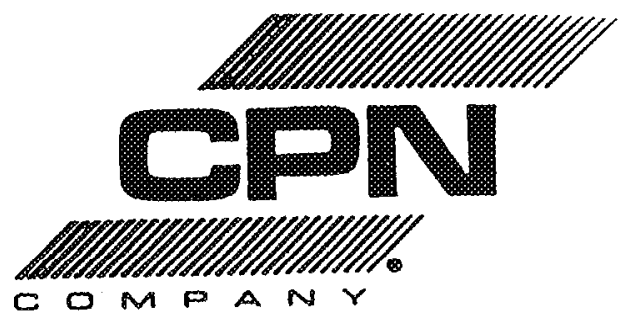

\section{DR HYDROPROBE ${ }^{\circledR}$ MOISTURE DEPTH GAUGE}

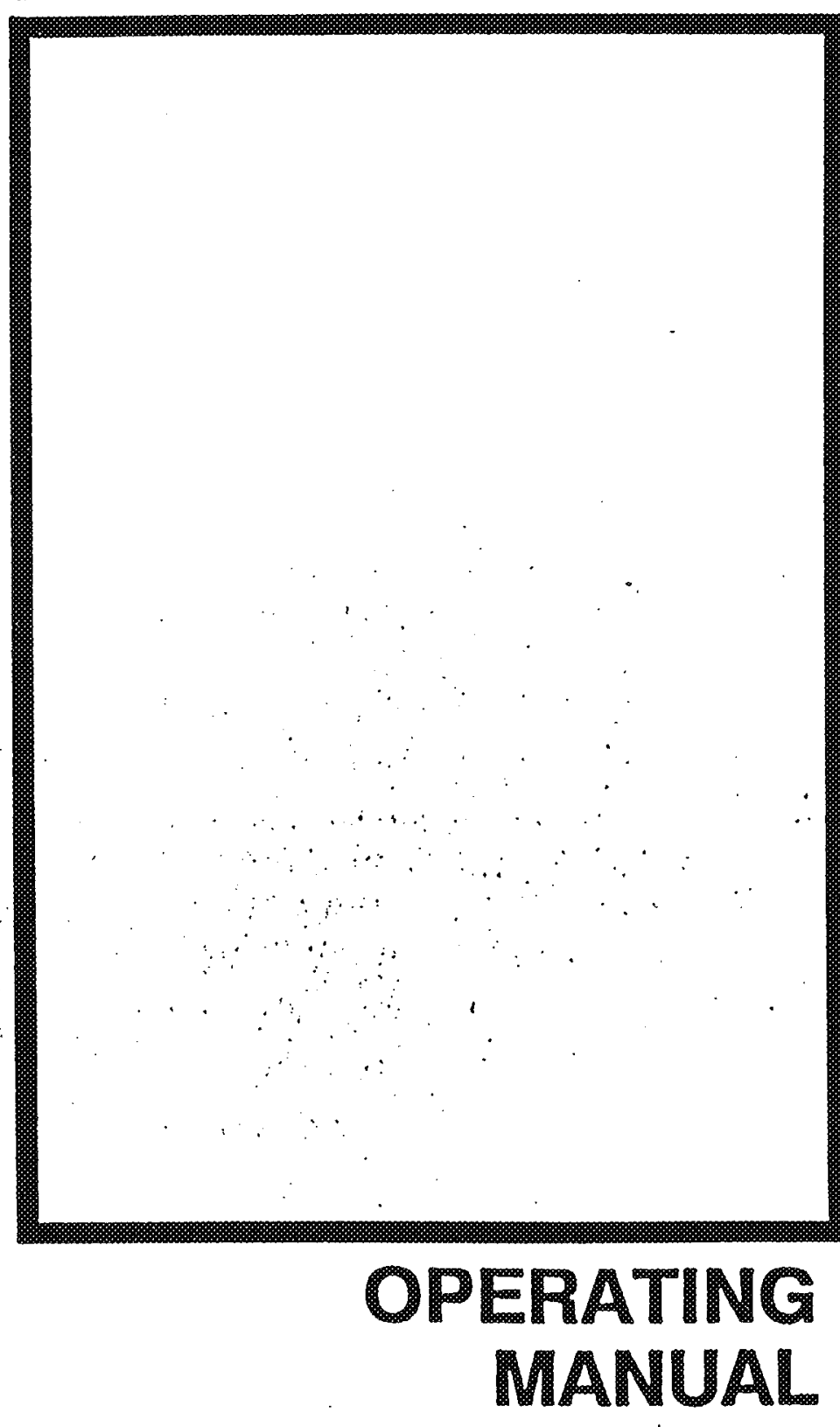

ny CAX (510) 228-3123

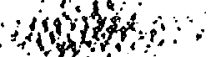





\title{
MANUAL CHANGE NOTICE 503DR
}

\author{
VERSION 503A-230
}

To take a standard count press: STD, step till the gauge displays "NEW STD?" and presS ENTER.

In Format the gauge now allows a record to contain 0 to 99 keydatas and 0 to 99 readings.

Selftest has been removed from the Menu.

While taking a count the display shows "COUNTING".

While taking a reading in Log Mode, the display shows "COUNT $N$ ", where " $N$ " is the number of the reading as defined in format and counts down to "q".

The displayed units are: CNT, RAT, PCF, GCC, \%V, IPF, AND CPC. .

There are now provisions for 16 calibrations. A calibration may be selected by pressing STEP until the number is displayed and pressing ENTER as described previously or by selecting directly. e.g. press CALBB, 12, ENTER to select the 12th calibration.

The Format command now displays the number of records of storage after the "SET FMT?" display. Press ENTER to complete formatting the gauge.

The version display now includes the model number. e.g. "503A-230".

The print dump format has been changed. The first line header include the new version. number. In PRINT LP a top of form command is issued after the header and calibration information and before starting the date print out. 


\section{WARRANTY}

CPN products are guaranteed against defective material and workmanship for period of eighteen (18) months trom the date of receipt by customer, or maximum of twenty-lour (24) months from the date of manufacture, whichever comes lirsi. Detector tubes. fuses, and batteries are guaranteed for (6) months from the date of shipment from CPN.

Upon their prepaid return, CPN will replace tree of charge any part found to be defective within these warpanty periods. CPN reserves the right to repair all defectivo parts at our iactory, or authorized CPN service facility.

This warranty is void if inspection shows evidence of abuse. misuse, or unauthorized repair. This warranty covers only replacemeni of defective materials and workmanship. This warranty does not cover damage caused by exposure to excessive moisture.

1f, for any reason, this unit must bo relumed to our factory for warranty service, please contact us for retum authorization and shipping instructions. Include with th shipment: customer purchase order number, CPN Company invoice number and date, sopial number of gauge and reason for retum. 
INSTRUCTIONS

TABLE OF CONTENTS

n GENERAL

(White Section)

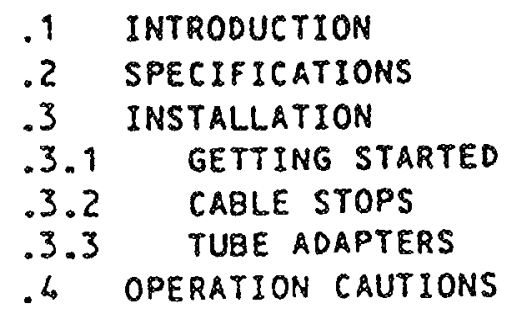

1 SPECIAL

i. 1 CALIBRATION

i.2 ERROR MESSAGES

APPENDIX

1 COUNTING STATISTICS

3 ORDUMP PROGRAMS

- CABLE HIRING DIAGRAMS 


\subsection{INTRODUCTION}

The MOdel 503DR HYDROPROBE, NEUTRON DEPTH MOISTURE GAGE measures the submsurface moisture in soil and other materials by use of a probe containing a source of high energy neutrons and a slow (thermal) neutron detector. The probe is lowered into a premdrilled and cased hole $(9.5$ or 2 inch diameter). Hydrogen as present in the water in the soil slous the neutrons down for detection. The moisture data is displayed directly in units of interest on an above surface electronic assembly which is integral to the source shield assembly.

The gage is supplied with a 12 foot cable and five adjustable cable stops. Additional stops and longer cable lengths are available.

Upon retraction of the probe into the shield, the probe locks automatically in place for transportation.

The complete assembly is supplied with a plastic shipping and carrying container which contains: accessory items, cable, instruction manual, charger, and other materials which the operator may wish to carry. 
PECIFICATIONS

NCTION:

$$
\Xi
$$

ECISION:

UNT TIME:

MP:

IWER:

ITTERY LIFE:

INSUMPTION:

:CHARGE:

ISPLAY:

ITA STORAGE:

ATA OUTPUT:

ALIBRATION:

NITS:

EUTRON SOURCE:

"CAPSULATION:

ELDING:

IHIPPING:

IPECIAL FORM

IPPROVAL:

:ONSTRUETION:

SURFACE UNIT:

PROBE: Model -2

$$
\text { Model }-9.5
$$

CARRYING

SHIPPING:
Sub-surface moisture measurements.

0 to $32 \%$ vol, $(0.32 \mathrm{gm} / \mathrm{cc}),(20 \mathrm{oct})$.

(3.84 in/ft).

$0.24 \%$ ar $24 \%$ vol at one minute.

1. 4, 16, 32, 66, and $256 \mathrm{sec}$.

0 TO $700 C$ oderating.

AA NICAD batter Dack $(0.5$ Ah) 8 cells.

500-1000 Charge-disenarge cycles.

$6.5 \mathrm{~A}$ avg. (allous more than

3000 each 16 sec counts).

Th hours at $\mathrm{C} / 10$ via wall charger.

8 character aloha/numerical Liquid-

Crystal Disolay. Easily

readable in direct sunbight.

3072 cells of: counts, identifiers,

or keyboard entry of auxiliary values.

Format operator programmable.

$0-15$ key and $0-15$ count per record

RS232C serial dump to external ppinter.

computer. CRT or coubler.

- user orogramed (linear).

User selectable:

ints, oct, gm/ec, vol, cm/30cm.

count and coune rario.

50 Ci Americium-249/8e

Double sealed Capsule, CPN-139

stlicon based paration

Radioactive Mrerial.

Special form, N.0.5., UN2974

Transpors index 0.9

Yellom II Label

USA Dot 7A. Type A Package

USA/0115/S

Aluminum with epoxy paint

or hardwanodize frinish.

Stainless teel wear parts

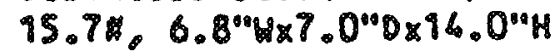

$(7.12),(172.7 \times 177.8 \times 355.6)$

$2.319 .865^{\circ 1} \mathrm{di} \times 12.7^{\circ} \mathrm{L}$

(1.063), (47. di $\times 322.6)$

$1.7 \%, 9.500^{\circ 0}$ di $\times 12.7^{\circ} \mathrm{L}$

$(0.779),(38.1 \mathrm{dig} \times 326.6)$

$36.5 \%, 24^{\circ 0} \mathrm{H} \times 93^{\circ 0} \mathrm{O} \times 10^{\circ 0} \mathrm{H}$

$(96.56),(609.6 \times 330.2 \times 256)$ 


\subsection{INSTALLATION}

\section{3 .1 GETTING STARTEO}

The stand-by power drain of the gage is less than the selfadischarge of the NICAD cells thus eliminating the need for a power switch. The DR is always $O N$. When first received it is recommended that the gage be placed on charge overnight to insure starting with a full charge.

You will have to set the gage to a configuration to meet your field conditions. To assist in understanding the gage initially, it is shipped from the factory in the following configuration:

$\begin{array}{ll}\text { UNITS } & \text { Inches per foot } \\ \text { TIME } & 1 \text { second } \\ \text { CALIB } & \text { H1 Factory calibration in saturated and dry sand. } \\ & \text { A (slope) approx } 2.5 \text { in/tt per countratio } \\ & \text { and B (intercept) approx } .06 \text { int } 7 \mathrm{t} \\ \text { STD } & \text { Standard count approx } 10000 \text {. } 6 \\ \text { FMT } & 1 \text { ID, } 1 \text { Keydata and } 3 \text { Depths allowing } 279 \text { records }\end{array}$

With the gage sitting on the nameplate on the shipping case press START. The gage should take a one second count and display the equivalent mois ture of the wax in the shield. It should be approximately 2.4 inches per foor.

Most of the commands are RERD/STEP/WRITE. That is, when first called up you read the display to see the current value step to a new value and then write (enter) the new value into memory. Try this by using the. following keystrokes to change the time from 1 to 96 seconds.

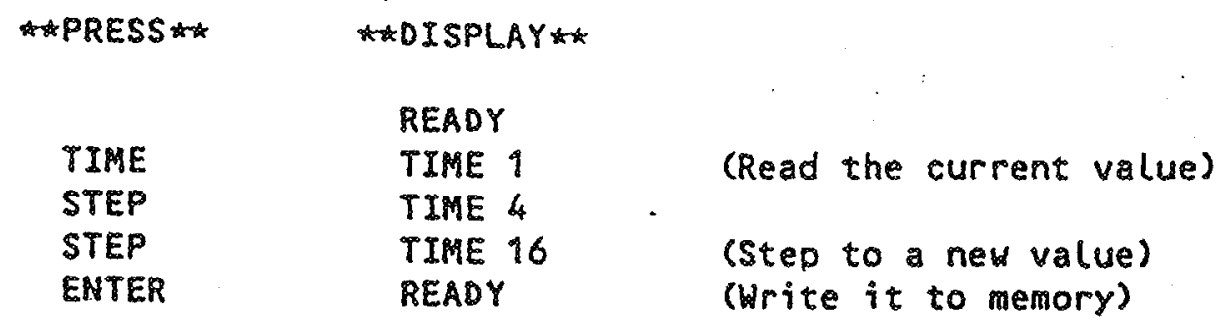

Do the same for Units, changing from Inches per foot to $\alpha$ Volume.

$\begin{array}{ll}\text { \#PRESS } & \text { \#DISPLAY } \\ & \text { READY } \\ \text { UNITS } & \text { UNIT IF } \\ \text { STEP } & \text { UNIT CC } \\ \text { STEP } & \text { UNIT \% } \\ \text { ENTER } & \text { REAOY }\end{array}$

Take another count by pressing START. The measured result should be the same as above except that the count should take 16 seconds and the display should be approximately $20.0 \%$ moisture by yolume (bhich is equivalent to 2.4 in per foot in the reading above). 
Please read the reasinder of this manual

ction 2.5 .1 is task orienced and describes the steps to use the gage , take readings. When you are ready to take it further and log adings, read section 2.5.2.

ctions 2.1, 2.2, and 2.3 are function oriented describing what each y does.

ctions 2.9 contain the necessary information to hardware interface the sge to a computer or printer.

:ctions 2.7 and 2.8 cover the software interface information.

\subsection{CABLE STOPS}

1e gage is supplied with five each clamo cable stops. This will allow taking sasurements at one foot increments in a sot zone up to five feet deep. For a seper root zone or for smaller increments -der more stops. Fig 1.3.2-1 shous -ossmsection of the gage. Use it to ssition the first stop so that the ament point on the probe (ss indicated $\checkmark$ the band) is in the middle of the too sot of the root zone. Its actual location ill depend upon how high the access rubes rick out of the soil. Install all tubes he same distance.

or example, if the base of the gage is $.0^{\prime \prime}$ above the soil and you want to take ne first measurement t $6^{\circ}$ olsce the top at $5.35+5.0+6.0=16.35^{\circ 0}$ above he stop peference line.

\section{.3 .3 TUBE ADAPTER RING}

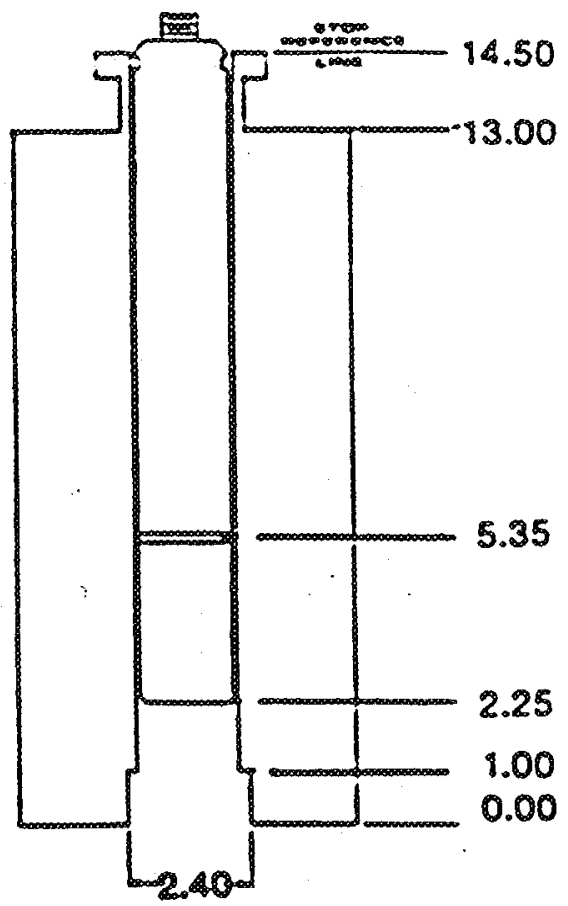

he botrom of the gage contrins oversize hole to allow inserting an dapter ring with dianetep to teh the type of access tubing being sed. The ring is secured by scres through the front of the casting. nless specified otherwise time of order, an adapter ring for alumium tubing will be suoplied. Adapter pings for other type le.g. iameter) are available from CPN Corp. or can be constructed locally. 


\subsection{OPERATION}

\subsection{CONTROLS AND OISPLAY}

10st functions are directly entered by pressing the appropriate key. Jptions are reviewed by STEPing, and selected with ENTER.

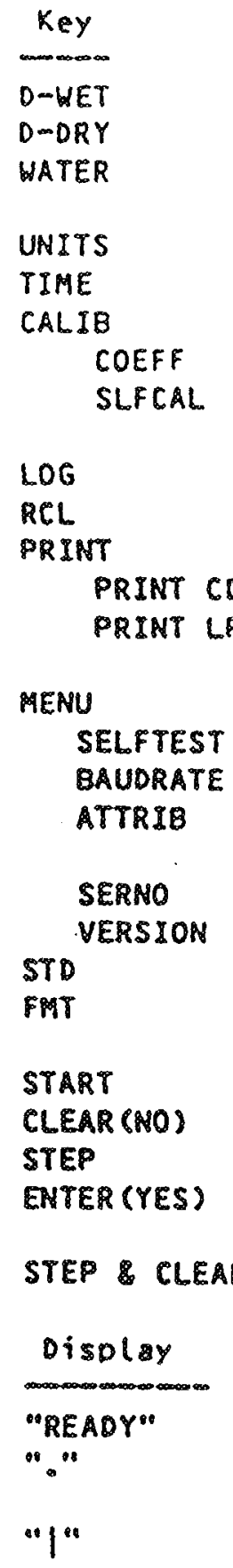

Function

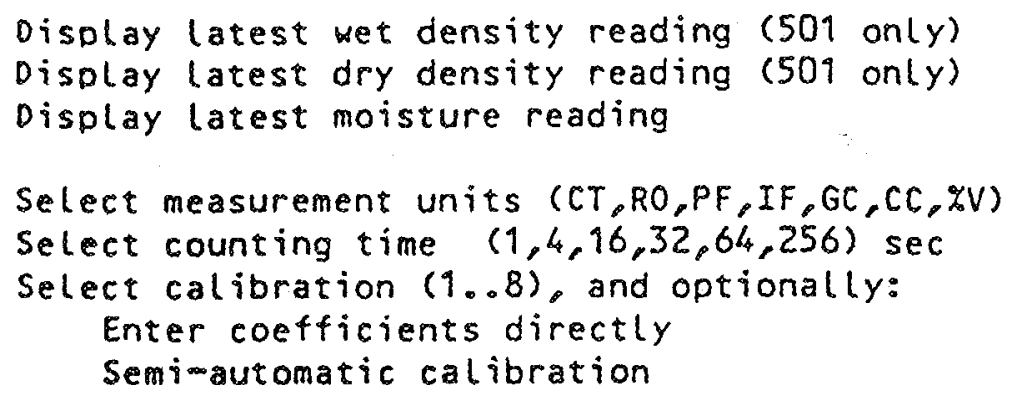




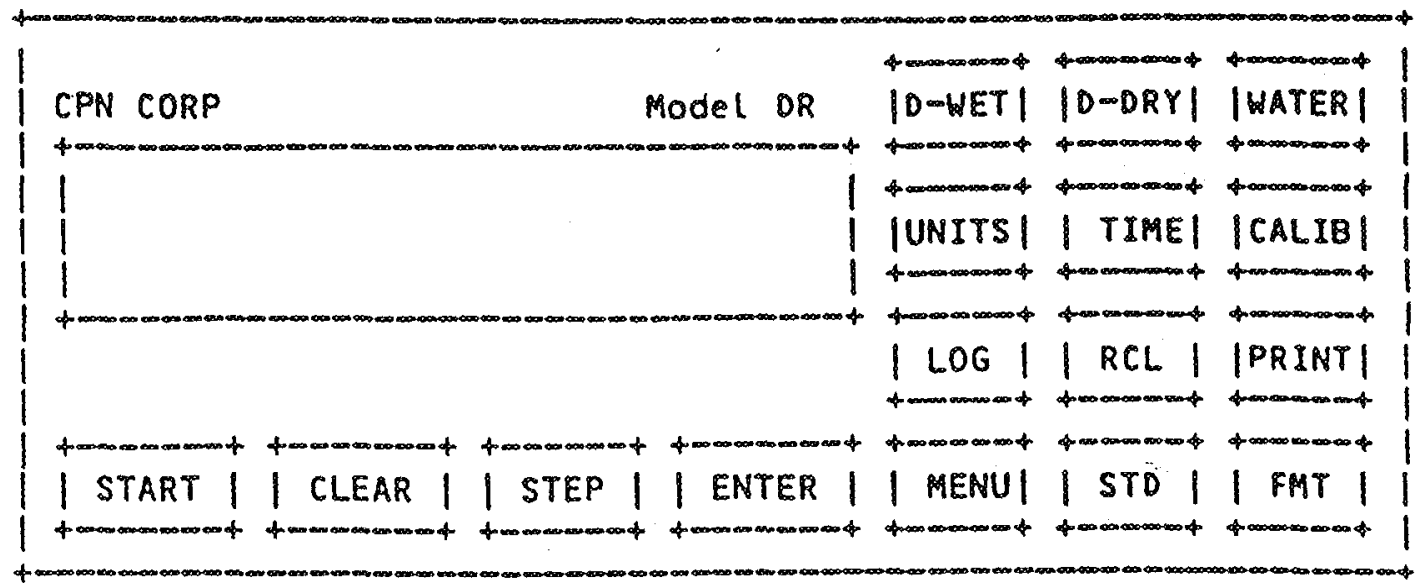

\subsection{KEYBOARD OPERATION}

D WET (501 ONLY)

Displays wet density using currently selected calibration and units (On a 503 returns to "READY").

D DRY (501 ONLY)

Displays dry density using currently selected calibration and units con a 503 returns to "READY"?.

MATER

Displays the most recent moisture reading in current units using current calibration e.g. "1234 $\mathrm{Cr}^{3}$. If number to be displayed is undefined (e.g. exceedes the display size) then "*." cr" will be displayed.

UNITS

Display/Select measurement unit. Displays current unit c.9. "UNIT IF". To select new unit, STEP to desired unit and press ENTER. If CLEAR or another selection key is pressed, unit remains unchanged.

$\begin{array}{llc}\text { Mne } & \text { Unit } & \text { Conversion } \\ \text { Cr } & \text { counts/unit-time( } 96 \text { sec disply) } & \mathrm{n} / \mathrm{a} \\ \text { RO } & \text { ratio (count/stdcount) } & \mathrm{n} / \mathrm{a} \\ \text { PF } & \text { ibs of water/cubic foot of soil } 62.428 \\ \text { GC } & \text { gms of water/cubic cm of soil } & 9.0 \\ \text { IF } & \text { inches of water/ft of soil } & 12.0 \\ \text { CC } & \text { cm of water/30 cm of soil } & 30.0 \\ \text { \%V } & \text { percent water by volume } & 100.0\end{array}$

The conversion numbers are shoun for reference only. The gage performs the conversion internally depending upon your seleco tion of units. . . . readings in gm/ce is divided by 1.0 and multiplied by 12 to get an equivalent reading in inches per foot. 
CALIB

Display/Select calibration (1 thru 8) and/or revieu/change its' coefficients.

Before pressing CALIB, select the appropiate units and time via the UNITS and TIME keys. If counts (CT) or ratio (RO) is the selected unit the gage will disDlay "SET UNIT". If SLFCAL is to be used to take count, select a time of 256 seconds for maximum precision.

TO SELECT A CALIBRATION

Acsive calibration is displayed on entry e.g. "CALIB 4". To select another calibration. STEP to the desired number and press ENTER. When the prompt "COEFFS ?" appears press CLEAR to return to "READY".

TO ENTER/CHANGE COEFFICIENTS WHEN THE COEFFICIENTS ARE KNOWN

Select the colibration number above. When "COEFF g" is displayed press ENTER. Coefticient "A" is the sloDe. "B" is the intercept in an expression of the form:

$$
\text { Display }=A \times(\text { ratios } 4
$$

Where ratio is count divided by standard count

Enter and using the sanits as previously selected by the UNITS key.

The current " $A$ " coefficient will be displayed. Press ENTER to aco ceot it or change it vi he nueral keys and press ENTER. Same for "B". Returns to "READY" fter last coefficient entered.

TO ENTER/CHANGE COEF ICIENTS HHEN THE COUNTS ARE KNOWN OR TO BE DETERMINEO

Select the calibration number above. Press STEP till "SLFCAL ?" is disolayed. Press ENrER.

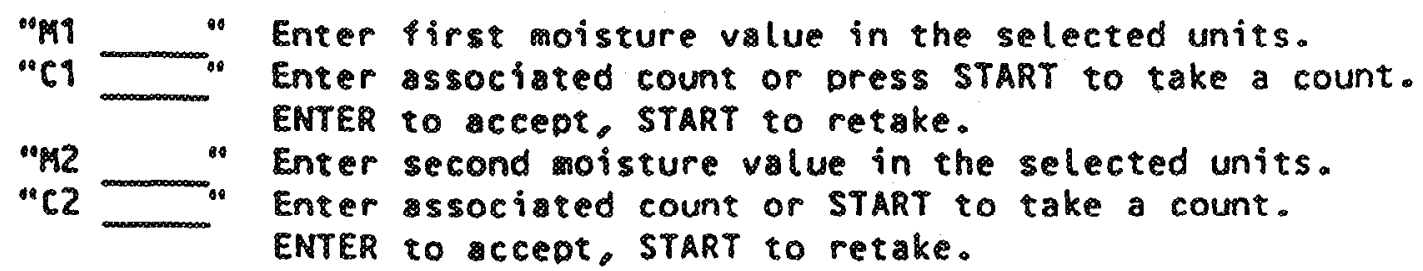

Either the low or high data par may be entered first. When taking a count olace the probe in the ppropiate moisture standard before pressing START. After coefficients are computed and stored, display returns to "READY". To review the coefficients use "COEFFS?". 
Arms the storage mechanism to $\log$ a tube site record. As defined previously by the FMT key, each RECORD consists of 1 each ID, 0 TO 15 keypad entries, and 0 to 15 depths. ID number, keypad entries and depths start at the highest value and down count to 1 . When LOG is first pressed the current record number is displayed. Press ENTER to use it as the default ID number or key in a meaningfull record number. The record number decrements from the maximum to 1 , each time a new record is logged. The record number is thus an indicator of how many additional records may be logged.

Keypad fields are read/modify/urite. i.e. it will first display what is stored in that location (normally blank for a new (ocation). Key in a value and press ENTER to store the new value. Press CLEAR to abort a wrong key entry. A keypad field may be skipped by pressing STEP.

Moisture fields are stored the same except that value is from a count initiated by pressing START. It may be retaken but will only be stored and advanced to the next field when you press ENTER.

A record is not stored in the log until the prompt "DATA OK?" appears and ENTER is pressed. If at that time you press STEP instead, the display will step around to the beginning of the rem cord allowing it to be viewed and edited. To accept an existing keydata or moisture value press ENTER or STEP. To change the data, urite over the keydata field followed by ENTER or press START for a new count followed by ENTER. The corrected record is finally stored when you press ENTER while "DATA OKg" is displayed.

RCL

To revieu the record log. On entry displays ID number of last rem cord logged. STEP back thru the log to the: ID number of desired record and press ENTER, or enter ID number directly. i... 1234 ENTER. If the keyed in ID number does not exist, displays "Not HERE". Press STEP to acknowledge and continue STEPing from last real ID. When desired ID is displayed press ENTER. Use the STEP key to move across the fields of the record llike a window moving across a tickertape).

Press CLEAR to step down the ID ${ }^{B}$. Press ENTER to return to the more detailed level. At the outer level you see the IDs only, at the inner level the entire record.

\section{PRINT}

Dumps record $\log$ to external device via the serial connector. For "PRIAT CQ" presS PRINT, ENTER. FOP "PRINT LP" presS PRINT, STEP, ENTER.

\section{PRINT CD}

Output formatted to upload record log to a computer dim rectly or via modem. Includes a line count and with each data line a checksum. Uses ACK, NACK software protocol to control transmission. 
PRINT LP

Output formatted for redability. Contains same information as Print CO dumo without the line count and the checksums and does not wat for response.

MENU

Step down the menu choices and presS ENTER to select a choice.

\section{SELFTEST}

Runs a comprehensive hardware check on the gage consysting of RAM test, ROM test, Counter test, Timep test, Disolay test and Keyboard test. The RAM rest is destructive. Do NOT run it if the LOG data is imbortant. Selftest takes about 2 minutes. You must watch the display test to see that all segments are the same. The keyboard test echos the key dad you touch. To comm plete the keyboard test press CLEAR quice. A successtul test will display "TST OK". If an error occurs, an error message will be displayed at the end of that test. To acknowlwedge it and continue the remaining tests press ENTER. To bort any test press CLEAR during the test.

\section{BAUDRATE}

Allows setring the baud rate for transmission on the serial connector. When first selected displays the baud rate cur rently selected. Use the step key to step to new rate and press ENTER.

\section{ATRIE}

Allows setring tributes into the PRINT LP outout for spem cific external equipment. Has provisions for 3 ach characters at the beginning of tranguission (prefix) and three each at the end (suffix). A typical orefix would be to transmit on ASCII decial 95 to an EPSON printer to olace it in the com pressed mode. A ryoical sutfix would be an AscI decinal 26, which is reconized by CP/M systew the end of transwission of file of data.

- Top of Form character (TOF) is crasmitred for each 60 lines of datr.

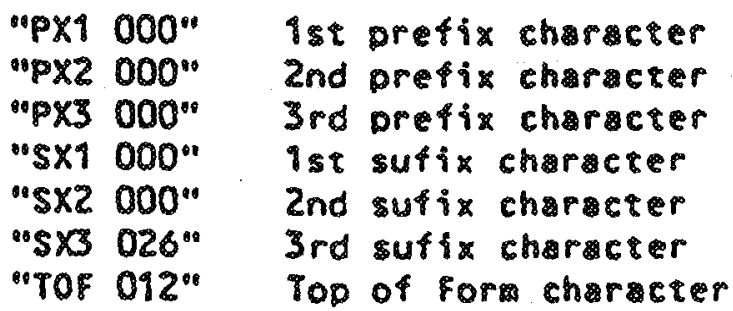

As stipped from the iactory the prefix and two of the sutix characters are nults (0). One of the sufix characters is a control Z (ASCII 26 for end of file in CP/M programs) and the TOF is control $L$ (ASCII 12). The ASCII characters are entered sheir decimal values $(0 . .0127)$ by keying them in and pressing ENTER> 
SERNO

Displays the last four numbers of the probe serial number. Press CLEAR to return to the READY display. The serial number may be change by keying in a new number followed by ENTER. This is useful when moving a surface electronic assembly from one gage shield/probe to another.

VERSION

Disolays the gage software version (useful for service Durposes).

Displays standard count information and/or take a new std count. Initially displays the current moisture standacd count (us). Step to display previous moisture standard count (MP). Step again to disolay the chi-square ratio of the current standard (MCHI).

(See section 2.6 for detailed procedures) To take a new standard count press sto followed by START. The DR will take 32 each 8 second counts, with a 2 second warmub delay between each count (6.27 minutes of counting). During each count period the previous count number and count are displayed e.9."24m-1234". When the last count is finished a NEW standard count based on the average of the 32 counss is calculared and displayed (it is displayed as an equivo lent 96 second count to be consistant with a normal count display, and so will be twice the previously displayed 8 second counts).

Use the STEp key to view the CURRENT standard count (identified as previous at this point) and HEW chiosq patio (continuing to press STEP will cycle the display around the three pieces of standard count information). If the difference between the new and current standard counts and the value of the new chimsq ratio are accept able press ENTER to updat the standard count information. If they are not acceotable press CLEAR to abort and take another new stan dard count.

To bort standard count in progress, press CLEAR several times uneil "ReAor" is displayed. The standard count information will rems in unchanged.

Disolay

$\begin{array}{ll}\text { "OMS } & 9234^{\circ} \\ \text { "MP } & 1199 \\ \text { "PMCHI } & 1.160\end{array}$

Description

Current standard count

Previous standard count

chicsquare ratio (stdodev) / (sqpomroot of std) 
Sets the record format, and clears the log soace. On entry. displays the maximum number of possible records to be logged in the current format. 6.g. "REC 279". Press ENTER. Key in the desired number of keydata entries ( 0 thru 15) and oress ENTER. Do the same for depths (0 thru 15). When the gage displays "SET FMT?" be sure you want to do it and then oress ENTER. This clear the log, sets the new record format, and start the storage at the top of the log area. Be sure you have dumped the previous information before clearing memory otherwise it will be erased. If you just wanted to view the current format but not clear it, press CLEAR to abort.

To display the maximum number of records under this new format, press FMT again. Press CLEAR to return the display to "REAOY" without changing or clearing the format.

\subsection{BATTERY}

The gage is powered by a replaceable NICAD battery pack $1500 \mathrm{mAh}$ capacity, 8 each cells). It is accessible by removing the four screws on the front panel. Also behind the front panel is circuit breaker. The red indicator should be showing for the gage to operate.

The charger, which is supplied with the gage, charges the rate of 50 aA. This $\mathrm{C} / 90$ rate will charge the gage overnight (16 hours) yet will not damage the cells if left on indefinitely. The red lamp on the chrow jer should be $O N$ and the charger should be warm to the the touch.

The 500 mah capacity of these cells will llow 3000 or ore 18 second. readings on a fult charge.

The gage should be charged any time the decimal point in the lower left if the display blinks or turns on or before going into the field two or lore weeks since the last charge (the cells have selfodischarge rate if $1 \%$ per day at room temperature). It should also be charged prior to laking a computer dump. The nominal battery voltage is $10.0 \mathrm{~V}$. The gage urns the low battery indicator on when the voltage drops to $9.60 \mathrm{~V}$. It ill not turn back off until the voltage has inereased to $10.60 \mathrm{~V}$ by echarging.

f the battery is allowed to discharge too low. the gage wll outowition ally go into a cutout condition to protect the batrepy cells. The dislay will show the lower vertical segement in the flpst character. The eyboard will be inoperative. The gage goes into curot at $9.40 \mathrm{~V}$ normally undep load). The cutoff circuit is restored when the cells ave been recharged to $90.40 \mathrm{~V}$. This takes about 20 mutes with $6 / 10$ harger. If cutoff occurs, charge the gage overnight and oress CLEAR.

efer to the service section of this manual for more on batrery cells. 


\subsection{OPERATING PROCEDURES}

\section{S.1 TAKING A REAOING}

To take a reading lower the probe to the appropiate depth and press START. Before doing this you must select Units, Time and Calibration. If you select any units orher than count, the gage must have a valid standard count.

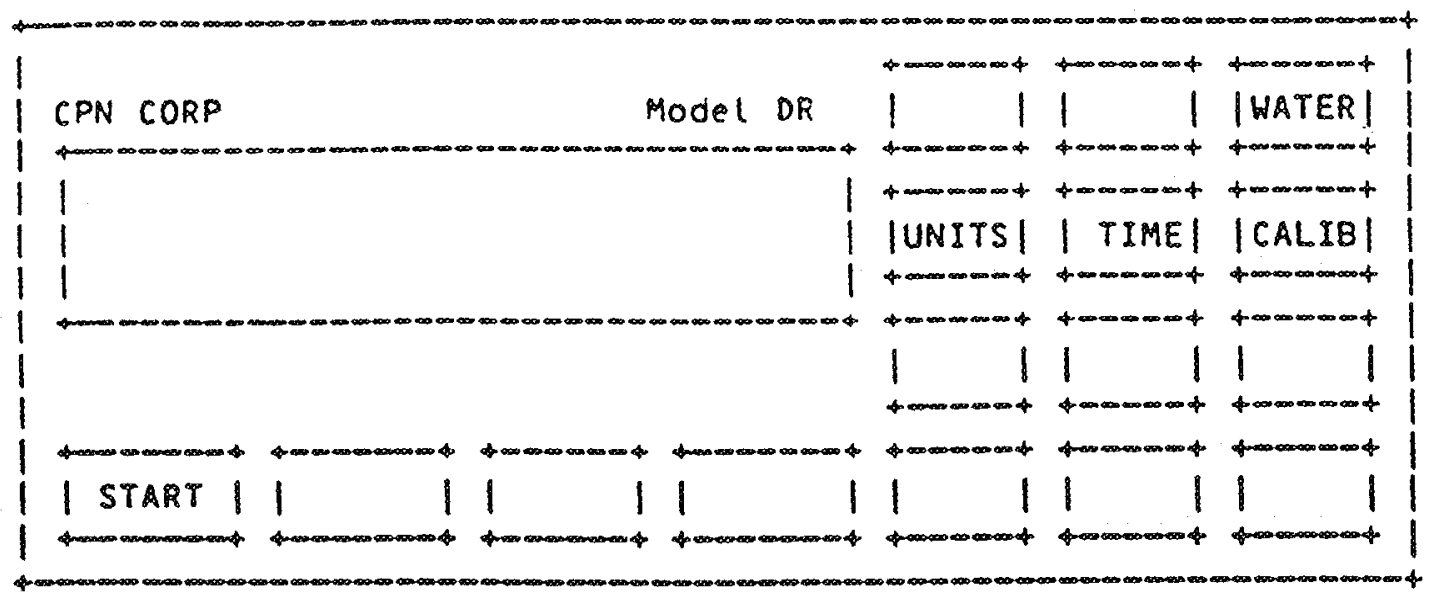

\section{UNITS}

The choic of display units will depend upon your use. Researchers will normally prefer grams per cubic centimeter or percent volume, while crop schedulers use inches per foot or centimeters per 30 centimereps. Counts are helpful for troubleshooting. It is the same or only differing by the conversion factor.

Once the units have been selected, then each time a count is taken the display will be in the units selected.

\section{TIME}

For given counting re the counting tio interval determines the precistion of the count. The longer the time, the more counts and thus the wore precise the count. Correspondingly the longer the counting time the less asurement that can be made in a day. Thus the time interval is normally selected as the minimum time that will not sacrifice precision.

For scheduling type operation count time of 16 seconds will provide sufficien precision to project the next irrigation date.

See the Dendix section on counting staristics for a further discussion of precision. 


\section{CALIBRATION}

The calibration will have been determined previously and the slope (A) and intercept (B) coefficients stored in one of the eight calibrations. Select the one that is appropriate for the soil and type of access tube.

TAKE A COUNT

Lower the probe to the desired depth and press STARr. While taking a count the gage will display the time, calibration, and units selected.

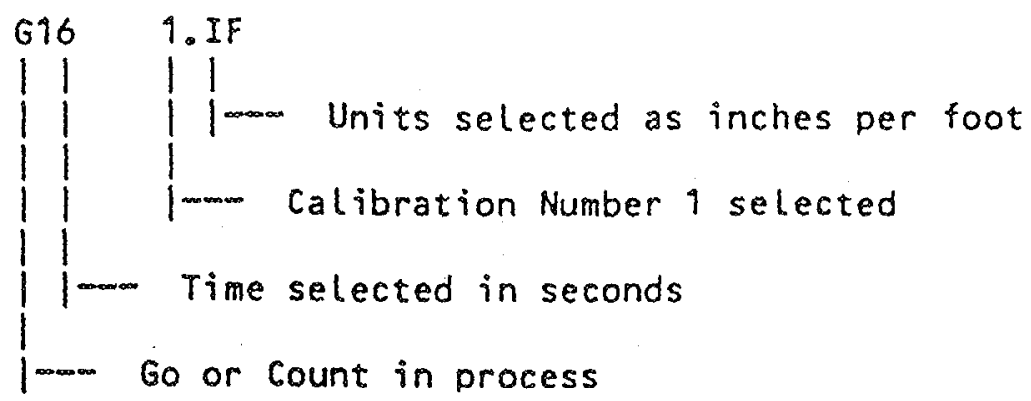

The gage will then display the measurement in the selected units. e.g. "3.88 IF"。

The last reading may be displayed at any time, in the currently selected units and calibration, by pressing the WATER key.

\section{5 .2 TO LOG READINGS}

Readings can be logged by the gage as they are taken in the field. Each tube site represents a record of information. Prior to storing any readings you must define the format of the tube site record. After readings have been logged, they can be recalled for display or dumped to an external device.

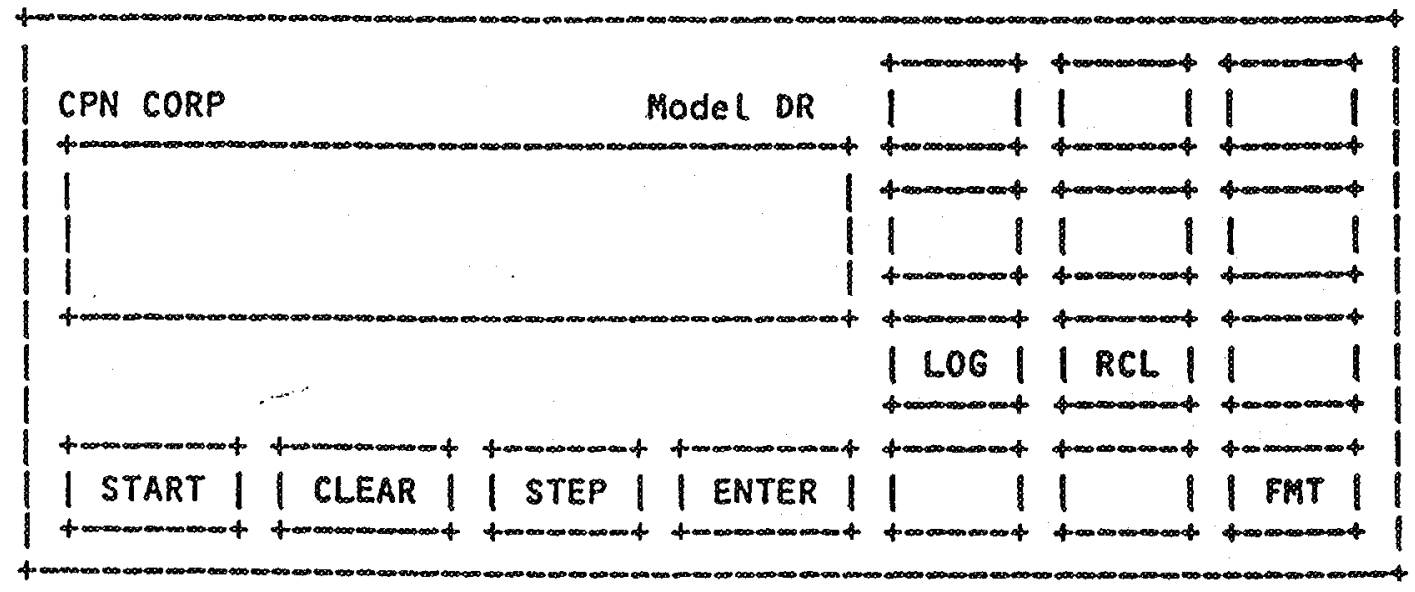


qube conditions. For each access tube at which one record of data is stored, the form will allow 0 to is keydata entries andlor 0 ro 15 rube depths (counts per tube). The gage always provides for an identifier number (ID) for each record and stores the selected calibration number $(1-8)$.

The toral memory space available is 3072 bytes. The number of byces required in a record for each qube site is as follows:

\begin{tabular}{lc} 
FIELO & BYTES \\
\hline ID & 2 \\
CALIBRATION & 1 \\
KEYDATA & 2 \\
DEPTH (COUNE) & 2
\end{tabular}

Thus a iypical tube site record format of of one ID, one calibration number, one keydata, and three depths (counts), cakes 11 bytes per record, and llows 279 records to be stored.

After the number of deoths is entered the gage will display "SET FAT?". Press ENTER to set the new format or CbEAR to abort. Setring new forar clears ll she data recorcs. DO IT EACH TIME A NEY SET OF OATA IS TO BE STORED.

Press FMT, ENTER, ENTER, ENTER, CLEAR to vies the number of records, keydatas and depths without clearing the data records.

\section{LOG/TAKE MEASUREMENTS}

Set units, time, calibration and format. Then to log a record of information, olace the gage on the access tube and press LOG. The gage will display the number of the current pecord into which data is to be logged. Since it down counes ir is also an indicarion of how many emory pecords poin.

You can use the gage generated number as the I0 numer to be stored by pressing ENTER. To enter your oun ID number for this pecopd (access cube) key in nuy nuber from 9065.535 followed by ENTER. It ay be aningtul to tre this nuber s wore than one number. i.e. consider the fipst two digits s farm number (allowing frow 1 to 65 farms) and the last suo digits as farm field number (allowing trom 1 to 99 fields on any farm). Enter the middle digis 0 or use it so indicar an operator number from $I$ to 9.

After entering the ID number the display will orompt for keydata entry 6.g. "Kg " Keydat entries llow you to use the gage to key in auxiliary in formation such as temperature, rainfall ecc. This feature helps liminate eprors in translating readings to note pads and then from the note pad to the computer. (It is recommended that all field dat be hand recorded to prevent loss due to subsequent equipment tailure).

Enter the keydata as number from 0 to 65.535 followed by ENTER. 
Aga in it may be treated as more than one piece of information. i.e. first two digits for temperature in degrees celsius and the last two digits for rainfall in inches. A keydata field does not have provisions for decimal points. They must be implied not entered directly.

Use any scheme which fits your field conditions. Just be consistant from record to record. The Irrigation Water Management Program available from CPN Corp. provides for entering the date for a series of readings by setting the ID to "O" and the first keydata to the date. e.g. 412 for April the 12th. Press ENTER without taking counts to skip the depth readings for this special record. ALl records following until the next ID of "O" are then access tube readings. The IWM program expects that the farm number times 100 plus the field number will be stored in the ID and the site number in the first keydata. e.g. for farm " 1 ", field "2" and site " 3 " the ID would be 902 and the first keydata would be 3.

If you make an error in entering a number, press CLEAR and enter the correct number. If you press CLEAR more than once in succession it will cancel the record storage without saving any of the record and return to the "READY" display.

If the gage does not accept the number (e.g. you try and enter a decimal point) it will give a multiple beep and remprompt. If it does accept the number it will prompt for the next keydata or if ll keydatas are entered it will prompt for a moisture reading by displaying "TAKE $M \#$ (H is the number of the depth position and will down count from the maximum number set via FORMAT to 1).

Lower the probe to the correct depth and press START. The gage will. display during counting as follows:

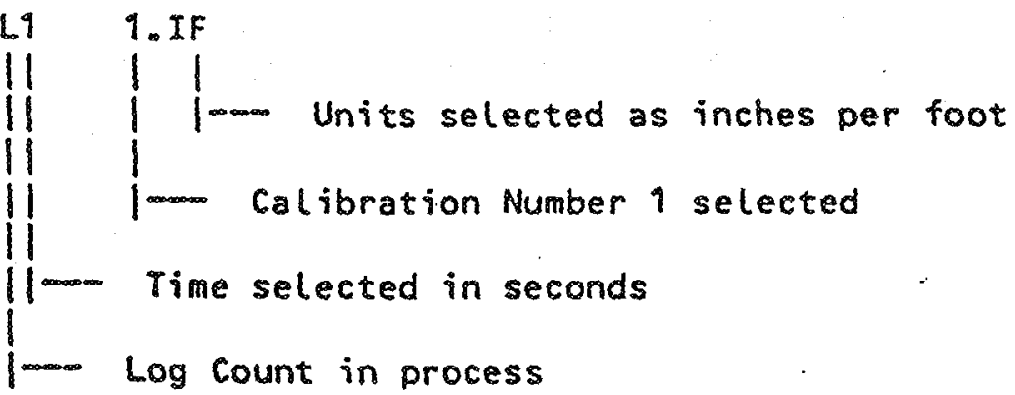

When the count is completed the gage will display "MH" and the value of the reading in the units selected e.g. "M3 $2.6538^{\prime \prime}$. If the reading is acceptable press ENTER to store it. If not acceptable identify the reason and press START to take another. Thus the gage will only store a reading if you accept and enter it. The display will then prompt to take the next depth moisture reading. Move the probe and repeat the process by pressing START. Continue in this manner until all depths have been recorded.

If you want to skip depth (e.g. the bottom depth is flooded) press STEP instead of START/ENTER. This is also useful if you have some tubes with five depths and some with only three. Format for five and skip two readings when on a tube with only three depths. 
If the units "If" or "CC" have been selected then after the last depth has been entered or stepoed over. the gage will totalize and display the TOTAL mosstuRe in the root zone in inches or co. "TM $96.437 "$ "

Press STEP or ENTER and the gage will disDlay "DATA OK?". Press ENTER to $\log$ all the data for this record. The disolay will return to "READY". If the data is not correct press sTEP until the bad data is displayed (the display will start with the ID and skip across the record). Correct it by a keydata entry or taking and entering a new count. If you press CLEAR when "DATA OK?" is displayed then the logging of that record will be aborted and all data for that record cleared.

Use the ENTER or STEP key to skip to the keydata you want to change or take a new count. When you again reach the end of the record and "DATA OK?" is displayed press ENTER to log that record.

\section{RECALL A RECORD}

Normally the stored data will be oumped to princer op computer. It may also be pecalled to the display by the RCL key. When first entered it will point to the last ID stored. Either use the STEP key to step up the ID IjSt (it steps back thru the list and circles around at the begining or ky in specific 10 and press ENTER. Use the stepkey to move across the record. If you continue pressing STEP the display will advance wo to the mex record and then across etc. 


\subsection{STANDARO COUNT}

The standard count is a measurement of the hydrogen in the wax in the shield. By taking it in exactly the same manner each time, it provides two means for checking the validity of the counting function.

1) By comparing it with the previous standard count to see that it has not changed more than an acceptable amount, it is an indication of acceptable drift of the electronics. Americium-241 has a one-half life of 458 years. It's decay rate is negligable.

2) By taking it as a series of short counts rather than one long count and verifying that its statistical distribution is normal, it is a means of checking that noise is not influencing the count.

\section{PREVIOUS STANDARD COUNT}

Whenever a new standard count is taken, the DR automatically holds the current standard count in the previous count memory. This allows for comparing the new count with the current count. The difference between the two counts should be within 0.707 of the square root of the average of the two counts $95 \%$ of the tiale.

Exaple: The current standard counts is 94400 while the previous standard count is 14450 . The difference between the two numbers is 50. The squarearoot of the average of the curpent standard count is 120.1 Cone standard deviation). Since 50 is less than $85,10.707$ times 120), the two counts are within acceptable limits and there is no reason to believe the gage is malfunctioning.

it is more or if it is continuously changing in the same direction it ndicares that service be warranted.

\section{AKING A STANDARO COUAT}

ith the case on the ground, place the gage in he con nameolare depression on the top of the se. No other radiometive sources should be ithin 30 feer of the gage and no source of ydrogen should be within 10 feet of the giuge. he operator should stand back 90 feet after barting the reading.

2 initate new standard count press STD and ren START.

ve wax in the shield is not an infinite slume. Thus a standard count taken in this mner is subject to surrounding conditions. It ; important that the standard count is taken 1 the same conditions as that used to estab-

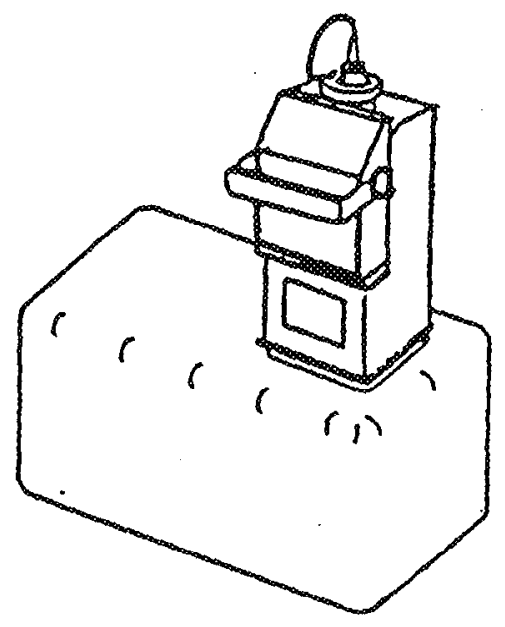


lish the calibration and that the conditions are the same each time.

A more stable method to take a standard count in an access tube installed in $30 \mathrm{gal}-$ con or larger water barrel. To use the factory calibration but change to a new method of taking a standard count, modify the " $A$ " calibra" tion slope term by the ratio of the new stan dard count and the factory standard count. e.g. the original factory standard count was 19,000 with an "A" slope of 2.6, while the new water barrel standard is 33,000 . The new "A" coeffim cient should be:

$2.6 *(33,000 / 91,000)=7.8$

The verification reading of the wax in the shield as per section 1.3 .1 should be the same.

When a standard count is started, the gage will take 32 each 8.0 second counts turning the HV power supply to the probe on with each count. With each count, the display will show the count number $(32,31,30, \ldots \ldots, 1)$ followed by the actual 8 second count e.g. "30 7200". When the 32nd count is completed the NEW standard count is displayed e.g. "Ms 14400". It is cormalized to a 16 second count time the same s a normal display count.

Press the STEP key to view the CURRENT standard count e.g. "PS 14500". Press the STEP key again to view the Chi-Sq Ratio of the NEW count e.g. "MCHI 1.16". Continuing to press STEP will cycle the display thru the three pieces of standard count information. To update the standard count press ENTER while the display is in this loop. The current standard count will be stored as the previous standard count and the new standard count will be stored as the curo rent standard count.

(Note that the previous standard count vieved above is actually the current standard count until you press ENTER to accept the new stano dard count).

To. exit STANDARO without updating the standard count press CLEAR. To abort a standard count in process press CLEAR several times until "READY" is displayed

If the gage is connected to a printer via the serial link (see section 2.9). individual counts and summary intormation will be printed 
ut as shown in fig $2.6-9$

\section{ISCUSSION}

aking such a series of 32 counes will result in a distribution of ounts around central value. The standard deviation is a measure of he spread of these counts about that central value. For a random evice, such as the decay of a radioactive source, the ideal standard ieviation should be equal to the square-root of the central value.

f the gage is working properly, then the measured standard deviation nd the ideal standard deviation should be the same and their ratio hould be 1.00. The chi-squared test is used to determine how far the atio can deviate from 1.00 and still be considered acceptable. This is imilar to expecting heads and tails to come up equally when flipping an nbiased coin but but accepting other distributions when only fliping a nall number of times.

or a sample of 32 counts. the ratio should be between 0.75 and 1.25 for 5 \& of the tests. Note that even good gage will fail 5 out of every 00 tests. If the ratio falls too consistently outside, it may mean that he counting electronics is adversely offecting the counts. Generally he rotio will be high when the electronics is noisy. This might be due - breakdow in the high volrage circuits or defective detector tube. he ratio will lso be high if the detector tube counting efficiency or he electronies is drifting over the measupement period. $i_{0}$. The averge of the first five counts is significantly different than the aver ge of the last five counts.

- will be low when the electronics is picking up a periodic noise such 5 might occur due to failure of the high voltage supply filter. This nould be accompanied by significant increase in the standard count ver its previous value. 


\subsection{PRINT}

- Jtputs the contents of the record log to an external device (computer, CRT Terminal, modem, printer, etC) via the RS232C serial interface connector.

Two forms are available:

PRINT CD - for dump to an active device such as a computer (or computer via a modem). Each (ine of data includes a check sum and requires a software response from the computer to insure proper transmission of data.

PRINT LP - for dump to a passive device such as a printer or CRT Terminal. Same as the Print CD except no checksum, and the next line of data is transmitted without waiting for a response from the receiving device. Also the data is formatted for ease of readability and header information is included.

PRINT CD

A simple software ACKNOWLEDGE/NEGATIVE-ACKNOWLWDGE handshaking scheme (ACK/control $\sim F$, NACK/control $-U$ ) allows the external device to control the dump: ACK echoed in response to a received line causes transmission of the next line, while NACK causes retransmission of the same line. ACK may be echoed as often as necessary to receive an error free line. characters other than ACK, are by default NACK. If the DR does not res. ceive a reply within 60 seconds after sending the carpiage return and line feed (CRLF) at the end of each line, a default ACK is assumed and the next line is transmitted. The computer should not echo the DR transmission.

The following table shows how long in milliseconds it takes to transmit one character at each of the possible baud rates. The program in the computer must be fast enough to receive, process and be ready for the next character within this time to insure not missing any characters. (See also section 2.9 for hardware handshaking which allows control of the OR transmission on a character by character basis).

\begin{tabular}{|c|c|c|}
\hline BAUD & $8 I T$ & CHARACTER \\
\hline RATE & $\mathrm{ms}$ & $\mathrm{ms}$ \\
\hline $\begin{array}{r}110 \\
300 \\
1200 \\
2400 \\
4800 \\
9600\end{array}$ & $\begin{array}{l}9.091 \\
3.333 \\
0.8333 \\
0.4167 \\
0.2083 \\
0.10417\end{array}$ & $\begin{array}{c}100.0 \\
36.67 \\
9.167 \\
4.583 \\
2.297 \\
1.1458\end{array}$ \\
\hline
\end{tabular}

It takes approximately $100 \mathrm{~ms}$ after an external device has transmitted an ACK or NACK, for the DR to respond and transmit another line of data. 
Each dumb line consist of a series of fields separated by commas, and rerminated by CRLF. The fields are variable in number and wicth. The last field is a checksum determined by summing the AscII decimal value of each of the characters in the line wo to and including the last comma.

A received line whose computed checksum agrees with the transmitted checksum is good and should be echoed by ACK, lse a loss of data is implied and NACK should be echoed.

As each (ine is being transmitted, (or retransmitted) its' line number is displayed on the $D R$. The line number down counts, giving an indicam tion of the lines remaining, e.g. "LINE $123 "$.

\section{PRINT CD Format}

The Print CD dump consists of 4 parts:

Line 1 Line count $(N+10)$, gage identification and record format.

Line $2-9 \quad 8$ calibrations.

Line 10an $N$ records

Line 1: Gage identification and format

Lines,5030R,Sn,Unit, Hs rd, , Chk

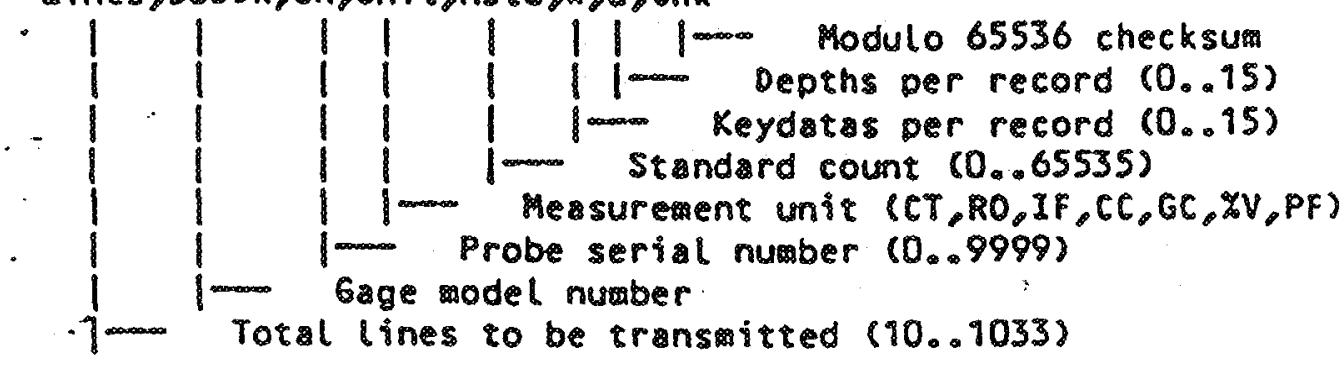

\section{Line 2 9: 8 Calibrasions}

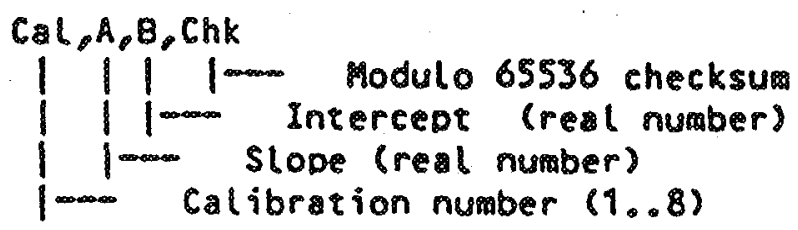


ne 90 - N: N Records

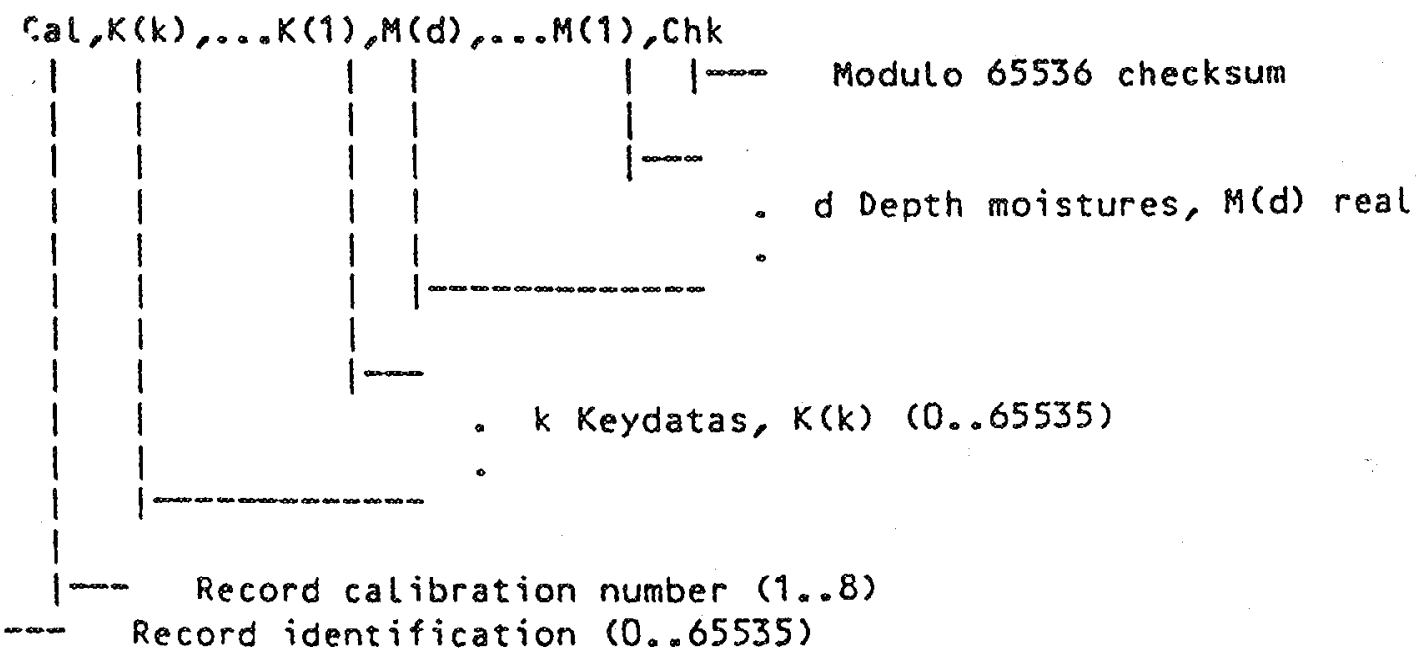

Sile image of a PRINT CO dump is shown in Fig 2.700. Note that all ita fields re separated by commas allowing easy use of input arements in BASIC or FORTRAN programs.

$$
\begin{aligned}
& 16,5030 R, 9999, \text { If, } 10000,2,4,1427 \\
& 1,3,0,-0.06,567 \\
& 2,2.5,-0.055,624 \\
& 3,3.0,-0.08,571 \\
& 4,3.5,-0.06,575 \\
& 5,8,8,0.0,857 \\
& 6.0 .0,0.0,470 \\
& 7,0,0,0,0,471 \\
& 8,0.0,0.0,872 \\
& 2963,1,0,0,0.0,0.0,0.0,0.0,1273 \\
& 11001,1,20,5,6.804,4.946,6.65,3.31,1716 \\
& 11002,1,20,0,3.388,1.15,1.097,1.61,1699 \\
& 11003,1,20,1,2.229,1.822,1.826,1.702,1796 \\
& 11004,1,21,2,2.887,1.855,1.966,2.191,1830 \\
& \$ 273,1,2,0,0,0,0,0,0,0,0,0,1276 \\
& 7003,1,22,15,3.41,4.412,4.135,1.082,1758 \\
& \text { FIG } 2.7-1
\end{aligned}
$$

he print program requipes that the computer be up during the dump. This laces heavy drain on the battery. Charge the battery before dumping. 1 you believe the pack is up but not sure, connect the charger during he dumo. If the cutout circuit turns on during the dump the data is ot lost. charge the gage for about an hour and then resinitiate the iump.

me samples of computep programs as shown in Appendix B. The ones in SIC will typically operate up to 300 baud. The assembly language call or the actual transfer of data that can be used to 9600 baud. 
ich computer system will require special considerations. Most oderating 'stems and high level languages are not writren for real time reration. For example one BASIC interperter does not require defining a ring length but changes its length as data inpur requires it. For a isiness application this is convenient, but if it occurs while putting a record of information from the DR some characters will be st. By including an assembly program control of the hardware ENABLE put to the DR this can taken care of but such hardware control is not issible with a modem.

INT LP

dump to a printer or a terminal contains the same information as the INT CD dump except that: no checksums, no line count and it is rmatted for readability with a header and Top of form command every 60 nes. Print LP also transmitts three control characters at the begining $d$ tinree at the end of the transmission. These sign on and sign off aracters may be used to set external devices such as a orinter to a sired configuration. e.g. compressed print. These actributes along th the character reconized as top of form (TOF) are set via ATTRIB, a bomenu of MENU.

nes of data are transmitted one after another without wating for an K/NACK response. The receiving device should NOT echo the ansmission.

typical PRINT LP printout is show in Fig 2.7-2.

\begin{tabular}{|c|c|c|c|c|c|c|c|c|}
\hline KODEL & S/H & UHIT & MSTD & KDATA & DEPTH & & & \\
\hline 5030R & 9998 & If & 80000 & 2 & 4 & & & \\
\hline CAL & $A$ & 8 & & & & & & \\
\hline 1 & 3.0 & -0.06 & & & & & & \\
\hline 2 & 2.5 & -0.055 & & & & & & \\
\hline 3 & 3.0 & -0.08 & & & & & & \\
\hline 4 & 3.5 & -0.06 & & & & & & \\
\hline 5 & 1.8 & 0.0 & & & & & & \\
\hline 6 & 0.0 & 0.0 & & & & & & \\
\hline 7 & 0.0 & 0.0 & & & & & & \\
\hline 8 & 0.0 & 0.0 & & & & & & \\
\hline 10 & CAL & $x 2$ & $\mathrm{kl}$ & พ4 & ตร & $R^{2}$ & 118 & TOPAL \\
\hline 5263 & 1 & 0 & 0 & 0.0 & 0.0 & 0.0 & 0.0 & 0.0 \\
\hline 11001 & 1 & 20 & 5 & 6.804 & 4.946 & 6.65 & 3.31 & 21.78 \\
\hline 11002 & 1 & 20 & 0 & 3.386 & $1.1_{\infty}^{E}$ & 1.097 & 1.61 & 7.243 \\
\hline 11003 & 1 & 20 & 1 & 2.295 & 1.829 & 1.826 & 1.809 & 7.578 \\
\hline 11004 & 1 & 28 & 5 & 2.887 & 1.855 & 1.968 & 2.891 & 0.899 \\
\hline $5_{273}$ & 1 & 2 & 0 & 0.0 & 0.0 & 0.0 & 0.0 & 0.0 \\
\hline $700 j$ & 1 & 22 & 18 & 3.41 & 4.412 & 0.135 & 8.089 & 36.07 \\
\hline \multicolumn{9}{|c|}{$102.7-2$} \\
\hline
\end{tabular}

ile PRINT CD is prefered because of it's handshaking. PRINT LP can be ed to make a passive data transfer to comouter. For $\mathrm{CP} / \mathrm{M}$ based 
system wish a reader sort, set the baud rates to agree, set a Control 2 (ASCII decimal 12) atrribure in one of the three suffix characters, connect the DR to the serial Dort defined as RDR: (see section 2.9), and upe in the computer while in CP/M:

DPIP ORSO3.DAT =ROR:

Then presS PRINT, STEP and ENTER on the DR.

The data in the DR will transfer to the fille named DR503.DAT. It will be a literal file. You will have to strip out header information etc. 


\subsection{REMOTE OPERATION}

The DR may be operated remotely via the RS232C serial connector. Set the $O R$ and the external device to the same baud rate. If the $D R$ is in the command mode ("READY" is on the display) then any character on the serim al input line will activate the $D R$ without causing any action. The appropiate remote control character from the following table should then be sent to the DR. Because of the debounce sottware in the DR, the following character should be spaced at least $100 \mathrm{milliseconds}$ but not more than 60 secondsfrom the activate character. The DR will Derform the command and shut down.

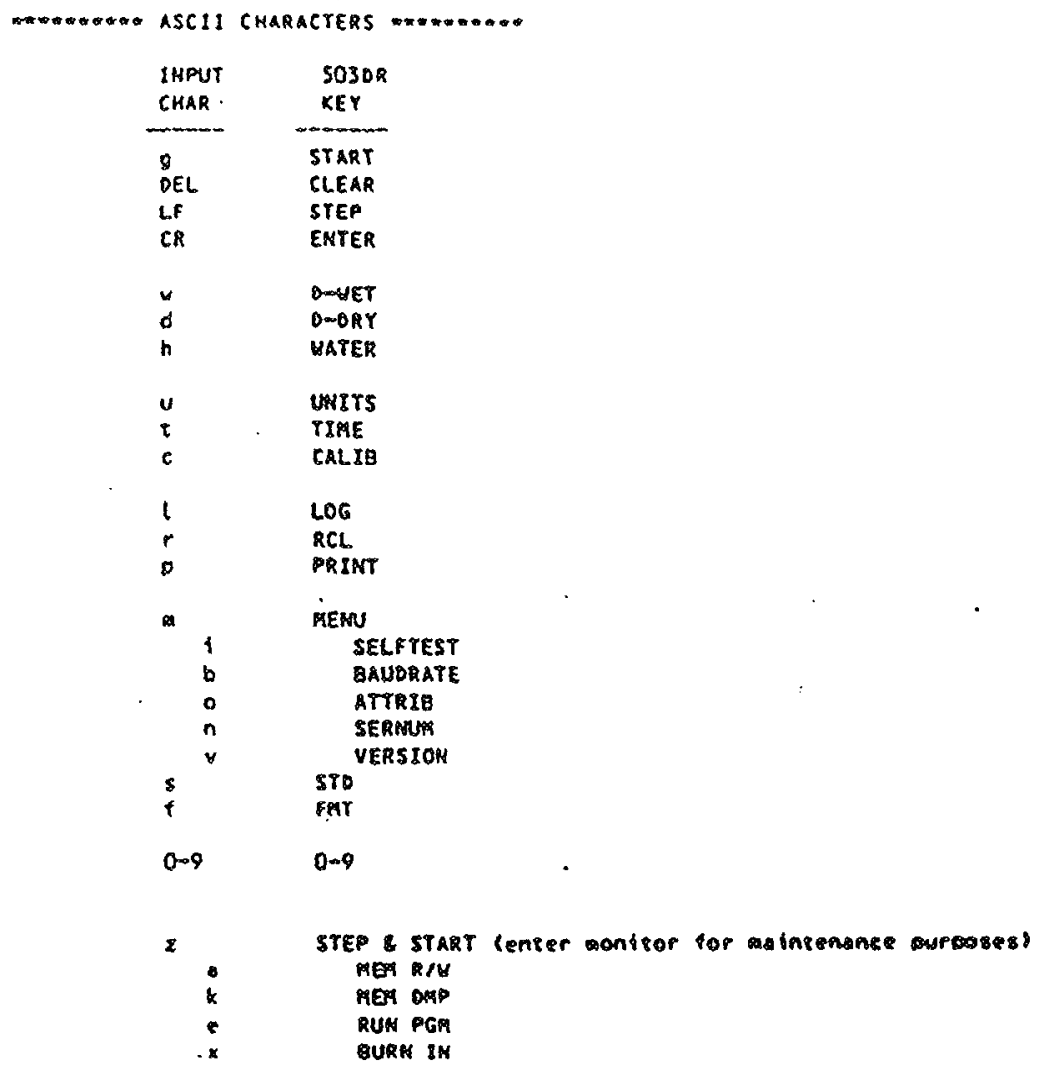

Control $R$ place the of in the cepainal mode lnower wo allowing to

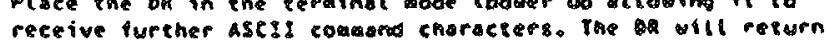

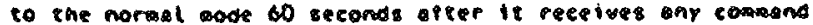

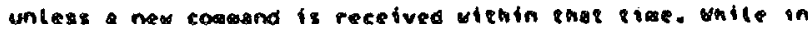

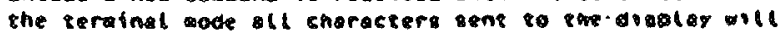
- also be trangaticed on the sepial owrowt limsl.

These commands $c$ an be used to control the OR from a CRT terminal or a special program can be uritten to control the DR from a computer.

introl-R is a special command that places the OR in the remote terminal sode. While in the remote terminal mode all information which opdears on the OR display will also be sent on the serial output line where it can 
we received by the control device. The $O R$ will stay in this mode for 60 seconos after the last command. If a sequence of commands are separated yy more than 60 seconds it will be necessary to send another control $\rightarrow$.

$r$ CP/M based systems with a peader/modem serial port. the XCOM command can be used to conirol the oR from the computer keyboard.

Example: To cause the or to start a count send:

99 (lower case "g" 100 millisecond delay then lower case " $g$ ")

The first "g" (or any character) activates the DR. The second "g" is reconized as the equivalent of pressing the START key.

Example: To set the Time to 16 seconds:

$$
\begin{array}{cc}
\text { DR } & \text { SERIAL } \\
\text { DISPLAY } & \text { OUTPUT }
\end{array}
$$

\begin{tabular}{|c|c|c|}
\hline${ }^{\circ} R$ & READY & \\
\hline${ }^{n} R$ & READY & \\
\hline$\tau$ & TIME 1 & TIME \\
\hline$L F$ & TIME & $=4$ \\
\hline LF & TIME 16 & 96 \\
\hline$C R$ & READY & REAOY \\
\hline
\end{tabular}

The first "Ro activares the DR. The second places the on in the remore cerminal ode. "q" causes the curpent time to be displayed and sent to the external device. If the external device is a terminal then the user ust vieu the display and key line-feeds (STEP commands) till the desired time is displayed then key carrage return (ENTER command). If the external device is a comouter, the program in the computer must do the same (the shoun above re actually backspace characters). The DR will peturn from the remote mode to the command mode 60 second after the CR or last comand is sent. 


\section{$\therefore 9$ RSZ32C SERIAL LIAK (hardwape description)}

The DR has the capability of two way communications over a serial link. his allows; 1) the data stored in the OR RAM memory to be converted to lard copy using a printer, 2) the data to be dumped to a computer for itorage and further processing before printing a hard copy report, and i) allows the DR to be controlled by the computer or a CRT terminal. The iccess to this serial link is through the ACCESSORY CONNECTOR located on he front of the surface electronic assembly.

\section{ACCESSORY CONNECTOR}

\begin{tabular}{|c|c|c|}
\hline PIN & FUNCTION & \\
\hline 1 & $+10 V$ & $\begin{array}{l}+10 V \text { from the } D R \text { for use by external } \\
\text { equipment (protected by the internal } \\
\text { circuit breaker) }\end{array}$ \\
\hline 2 & GROUNO & \\
\hline 3 & SERIAL DATA OUT & $\begin{array}{l}\text { Serial data from the } D R \text { to an external } \\
\text { device }\end{array}$ \\
\hline 4 & SERIAL DATA IN & $\begin{array}{l}\text { Serial data to the OR from an external } \\
\text { device }\end{array}$ \\
\hline 7 & ENABLE & $\begin{array}{l}\text { Control line from an external device to } \\
\text { the DR. When open or high the DR will } \\
\text { transmit the next character. When Low } \\
\text { the DR will hold transmission of the } \\
\text { next character until ENABLE goes high. }\end{array}$ \\
\hline
\end{tabular}

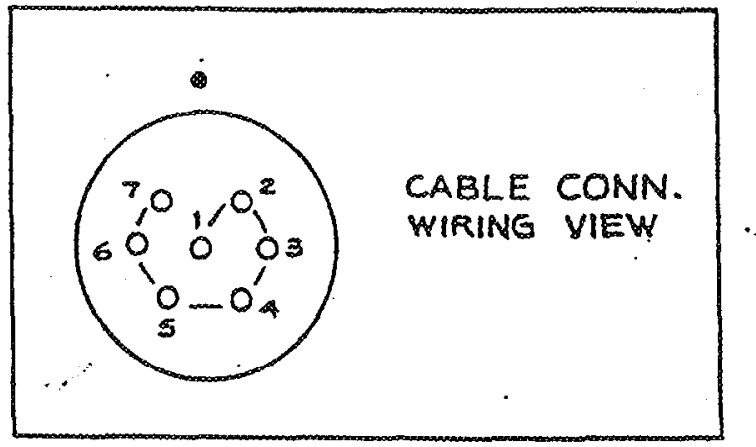

he DR transmits -4.0 volts for a MARK and +10 volts (battery voltage ctually ranges from 8 to 12 volts for a SPACE.

$\begin{array}{lclr}\text { NAME } & \text { VOLTS } & \text { LOGIC } & \text { RS232C SPEC } \\ * * * * * & * * * * * & * * * * * & * * * * * * * * * \\ \text { SPACE } & 10 \mathrm{~V} & \text { HIGH } & +3 \text { TO }+25 V \\ \text { MARK } & -4 \mathrm{~V} & \text { LOW } & -25 \text { TO }-3 \mathrm{~V}\end{array}$

he serial input to the DR accepts the standard RS232 voltage swing.

he ASCII code is 11 bits composed of: one start bit, 7 data bits, one arity bit which is always transmitted as a mark and ignored on eceiving (some users refer to this as 8 data bits and no parity), and 2 top bits. (the DR sends two stop bits and will accept one or more stop 
(s).

32326 defines connecror troes, oin assignments, signal voltage levels 1 timing for communications between oiece of data communications ipment (DCE) and piece of dara rerminal equioment (DTE). The con sctor should be a DPSS (temale) for ine DCE and DP2SP (male) for the TE. The DTE transmits on pin 2 and receives on pin 3 . The reverse is rue for DCE equipment.

52326 has worked well when aiece of terminal cavioment was working ith a modem. It has not been implemented consistantly when two pieces $f$ terminal equipment are interconnected and the cquipment designer mus: efine one of them as communications equioment. e.g. when a comouxer rives a printer. which is the DCE and which is the orE? All ombinations of male/female connectors and transmission/receiving Dins pe found.

he following 6 ft long cables, including boch a male and female version re available from CPN Corp. Also available are cable parts. Unless you lave provisions for soldering the small terminals in the circular conlector with 26 AWG wire, it is suggesteo that you order the unterminated able for special external device connecror apolicasions.

\begin{tabular}{|c|c|c|}
\hline PART NO & $\begin{array}{l}\text { DESCRIPTION } \\
\text { D }\end{array}$ & MATES WITH \\
\hline $\begin{array}{l}T 501544 \\
6501516 \\
T 501575 \\
R 618307\end{array}$ & $\begin{array}{l}\text { Cable, RS232C10P25P } \\
\text { Cable, RS232C10P2SS } \\
\text { cable. RSZ32CIunter } \\
\text { Connector ch. 7oin }\end{array}$ & $\begin{array}{l}\text { DP25S } \\
\text { DP25P } \\
\text { ted }\end{array}$ \\
\hline
\end{tabular}

The wiring of these cables is shown in Apoendix C a long with some specific hardware configurations. If your configuration does not. fit any of these cables available from CPN, order one with the proper connector type (male or temsle). Then rewire the oins seauired.

The ENABLE LINE is ovail ible for hardwre control of the transmission on char cter basis. Most external equipment require the ENABLE line wired to Din 4 of the DP2S connector for an RTS orotocol. On some it will be niecessary to wire it to pin 20 for a OTR orotocol.

If hardware handshaking is not required. leave the ENABLE line open. The OR has an incernal oull wo ro ol ace it in the proper state. The circuit for the ENABLE inout (also the serial input) is shown in fig 2. $9-1$.

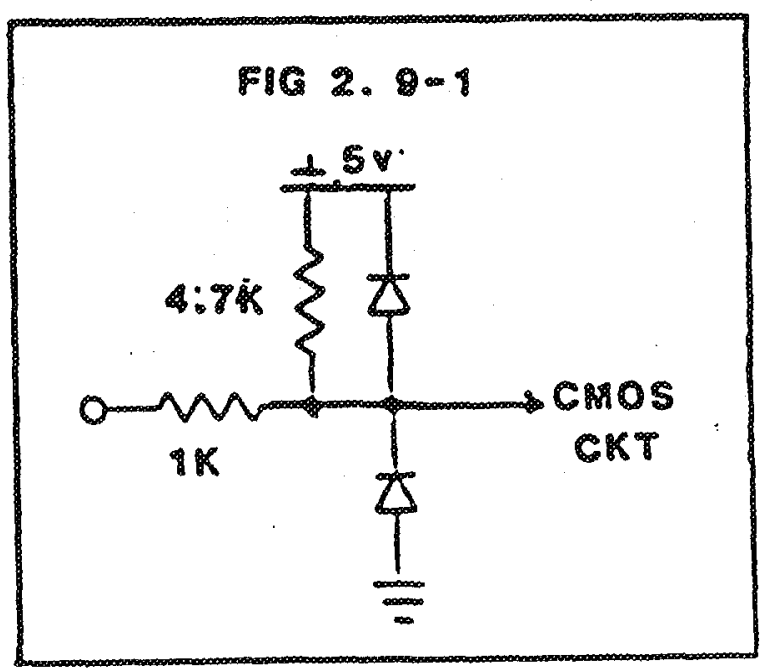

The inout control oins to the external device should be wired to either the mark or space condition as aporooiate to allow dara to flow.. Typically this will involve wiring pin 5 (CTS) and pin 6 (OSR) to the sace $(\$ 90 \mathrm{~V})$ condirion. 


\subsection{SPECIAL}

\subsection{CALIBRATION}

The neutron probe is a source of fast or high energy neutrons and a detector of slow or thermal neutrons. The fast neutrons are slowed down by collisions with the nucelus of matter in the soil and then absorbed by the soil matter. Since the mass of the nucleus of hydrogen is the same as that of a free neutron, the presence of hydrogen will result in a high field of thermal neutrons. Heaver elements will also slow down the neutrons but not nearly so effective. While it takes on the average only 98 collisions with hyorogen, it take 200 with the next element normally found in agro soil.

The thermal neutrons are continually being absorbed by the matter in the soil. Boron for example has a high affinity for thermal neutrons. The resulting thermal neutron flux will depend upon a number of factors both creating and absorbing thermal neutrons, but most importantly will be how much hydrogen is oresent. The neutron probe may thus be used as a measuring device for moisture in the soil but it may. require calibration for local soil conditions.

\section{FIELD CALIBRATION}

A field calibration requires the probe, volume sampler, a scale and a drying oven. Install the access tube in a representative point in the soil. Take probe readings in the tube and volume samples in pairs around the tube. Take them the same depth and within a foot or two of the tube.

Seal the volume samples in a sample can or plastic seal bag immediately ster removing from the soil. Be carefull not to compact the surrounding soil wen raking the samples. Ideally 20 such measurement pairs should be raken over a range of moisure conditions.

An alcernate method is to use a samoler of smaller diameter than the tube and take volume samples at each depth while making the hole to insta ll. the ccess tube. Then take probe readings at the same depths. This has the advantage that the calibration is performed on the tube to be used for scheduling.

Another alternate, popular with irrigation schedulers is to only take two measurement pairs. one pair at field capacity and a second at a soil moisture condition near 50\% depletion. 


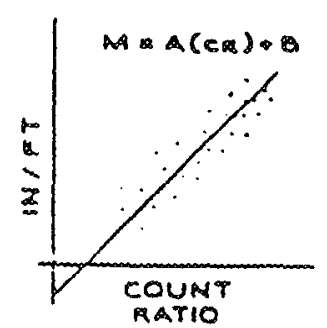

FIG $3.1-1$

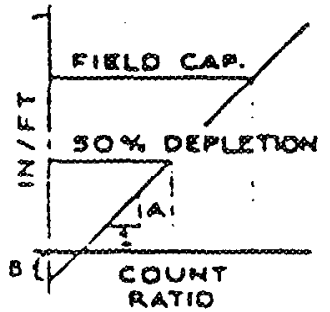

FIG $3 . j-2$

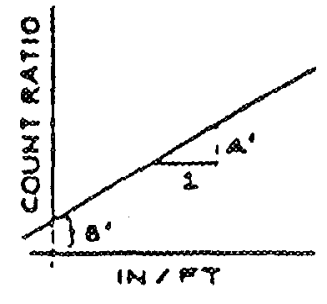

FIG $3.9-3$

Weigh the soil samples wet and dpy $(24 \mathrm{hrs}$ at 105 deg $\mathrm{C}$ in vented oven). Calculate the moisture by weight and the dry soil densigy and then combine to determine the soil moisture content in incnes pep foos as follows:

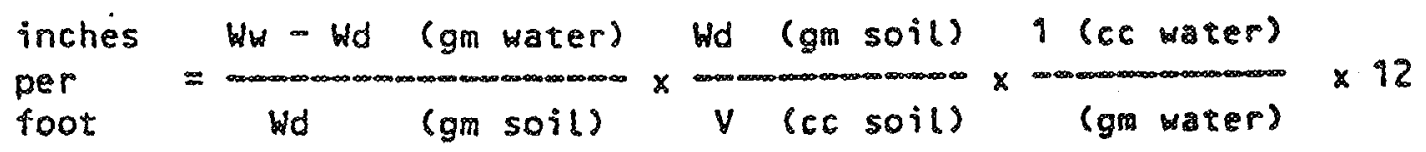

Using linear graph paper plot the probe readings in count ratio. versus the volume samples in inches per foot.

Fit the graph to a straight line. For scacter diagram of 10 to 20 reading pairs do a linear regression on a hand calculacor. For only two pairs use the following equations to determine the slope and intercept.

$$
\begin{aligned}
& \text { slope }=A=\frac{M H-M L}{R H-R L} \\
& \text { intercept }=B=M L-A \times R L
\end{aligned}
$$$$
\text { then: } \quad m=(A \times \cdot P)+B
$$

where:

$$
\begin{aligned}
& m=\text { moisture in inches per foot } \\
& r=\text { count ratio } \\
& M H=\text { high moisture value in inches oer foot } \\
& M L=\text { low moisture value in inches per foot } \\
& R H=\text { probe count ratio the high moisture value } \\
& R L=\text { nrobe count ratio at the low moisture value }
\end{aligned}
$$


Example: field capacity of 3.8 in/ft gives a ratio of 1.500 , wnile 50 dercent depletion gives a ratio of 0.77 .

$$
\begin{aligned}
& A=\frac{3.8-1.90}{1.5-0.77}=2.603 \text { in/ft/countratio } \\
& B=1.9-2.603 \times 0.77=-0.1043 \\
& \text { OR } \\
& m=2.603 \times r-0.1043
\end{aligned}
$$

\begin{tabular}{|c|c|}
\hline KEY & DISPLAY \\
\hline 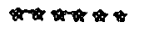 & 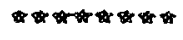 \\
\hline & READY \\
\hline UNITS & UNIT CT \\
\hline STEP & UNIT \\
\hline STEP & UNIT IF \\
\hline ENTER & READY \\
\hline CALIB & CAL I IF \\
\hline STEP & CAL 2 IF \\
\hline ENTER & COEFFS? \\
\hline EATER & $A * 0 *$ \\
\hline 2.603 & A 2.603 \\
\hline ENTER & $B \approx$ \\
\hline-.9043 & $B=0.9043$ \\
\hline ENTER & READY \\
\hline
\end{tabular}

Perform the following keystrokes to enter this calibration into calibram :ion numoer 2 .

The DR defines the slooe and interced with water on the vertical axis nd ratio on the horizontal $2 x$ is shown in Fig $3.1-2$. If you data has been vlorted with the axis reversed shom in Fig 3.9-3. it will be necessary to rranspose the slode and intercept terms before entering in The $D R$.

$$
\begin{aligned}
& A=1 / A^{\circ} \\
& B=0^{\circ} / 4^{\circ}
\end{aligned}
$$


- a laboratory calibration two known calibration points are needed. A igh calibration standard might be a barrel of sand saturated with water itypically $0.32 \mathrm{gm} / \mathrm{cc}$. i.e. 0.32 grams of water per cubic centimeter of soil or $32 \%$ water by volume or 3.84 inches of water per foot of soil). A con standard of dry sand would be $0.0 \mathrm{gm} / \mathrm{cc}$.

jet the gage to the desired units and select a $256 \mathrm{sec}$ count time. Use ine SLFCAL feature of the probe. Place the probe in one of the two known noisture standards. The display will prompt for the known moisture density of the standard. Enter it in the units selected e.g. 3.88 ENTER. If zount or ratio has been selected as the units, an error message will be tisplayed.

Pressing START will cause the gage to take and store a 256 secono reading. When the count is completed move the probe to the second mois ture standard. The display will promot for the moisture density of that standard. Press STRRT to take a 256 second reading in the second standard. When the count is completed, the gage will calculate and store the slope and intercept coefficients for the calibration in the selected units. Use "COEFF " ENTER to view them. Record them in your note book for future reference.

This is how the factory calibration was determined. It will be applica ble for sandy soils with no significant minerals or organics. It can so be used for relative measurements. e.g. measuring a field before .1d atter known irrigation will allow determining how much was applied versus how much the probe measures,before and after thus calibrating. the probe to that field.

\section{RANGE}

The linear calibration supplied with the $D R$ is useful over the most commonly used mositure range, 0 to $33 \%$. For special operation in mois ture percentages higher than this it is necessary to have special calibration. Fig $3.9-4$ shows a high range calibration. If field dar is not available, count in water barrel can be used.

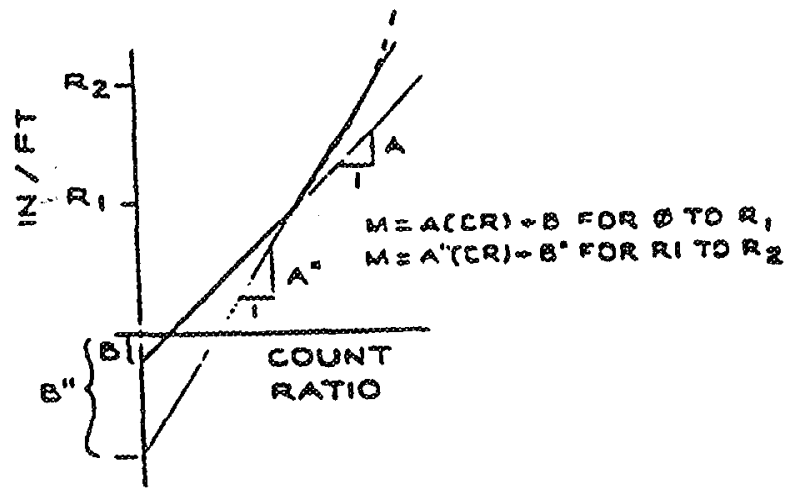

FIG 3.100 


\subsection{ERTOR MESSAGES}

14 en error occurs in the $D R$, then the function that was being performed is borted, and en errop descriotion or number is displayed (the gage is actully in the READY model. Errors that may occur in the normal operation of the gage, will disolay descriptive message. You should take corrective action as aporopiate.

Equioment errors that should seldom occur will display descriptive message or "ERR" followed by a number of 100 or above. If such an error number occurs, contact the factory or local service center.

IABLE - ERROR MLSSALES

Ooetating errors:

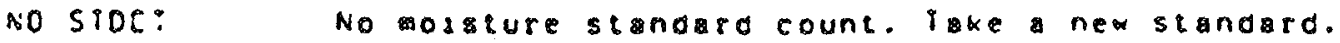

rULL

DOI HERE

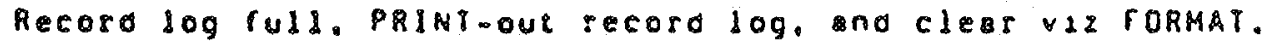

EHPYY

10 enterea snto RECALL does nos asis. Enter cassect ID.

NO DATA

Record log emoty when RECALL oressec. Losd secord(s) via LOC.

SET UNIT

Recoro log empey when PP.jit presgea.

Caliorasion coefficsents unaerfinec for Ci of RO unst. Cnange UNIT.

Internol Cneck (naroware) errors:

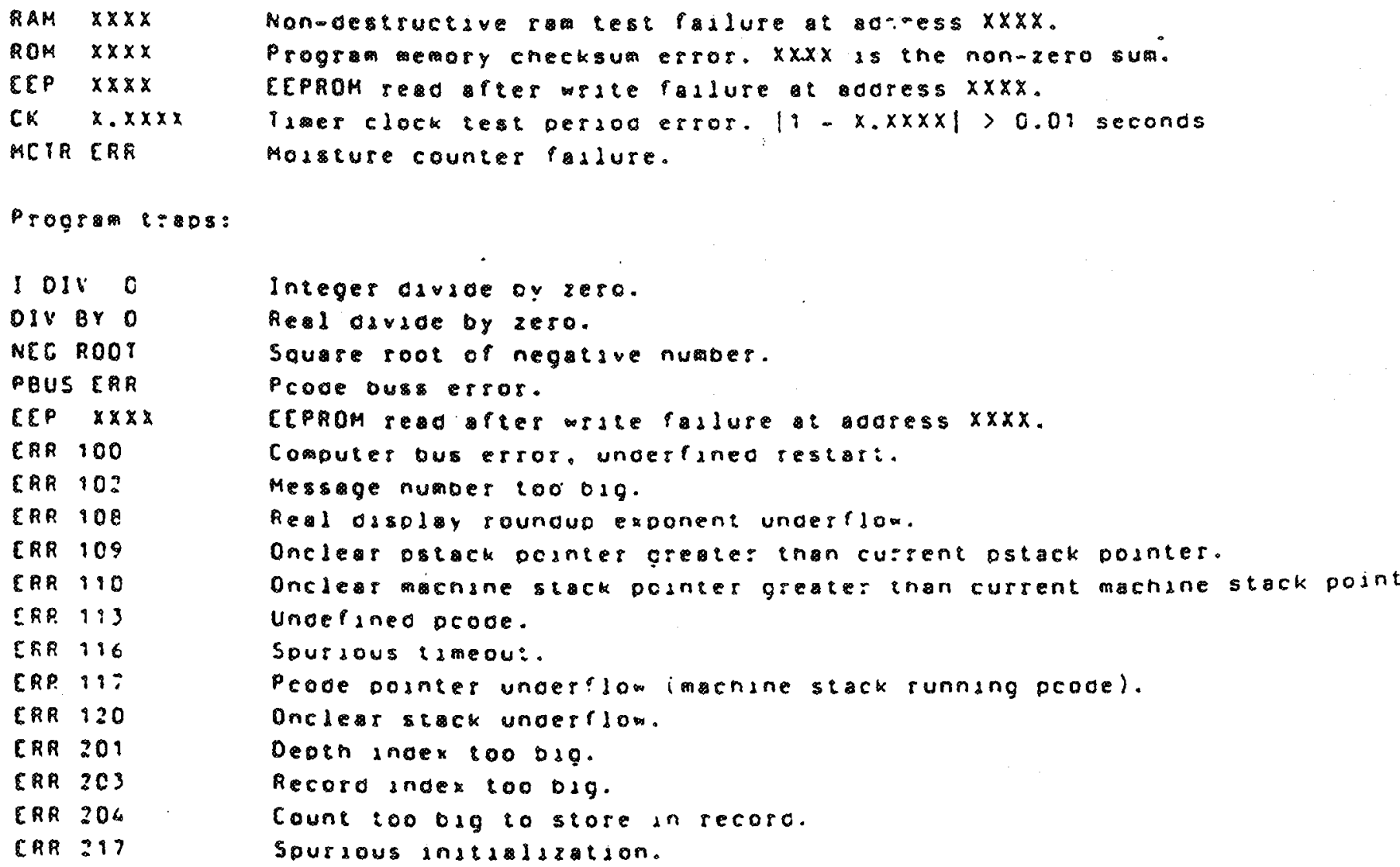

Integer oavioe oy zera.

hel olviae by zero.

square roos of negarave numer.

Pcone ous ersor.

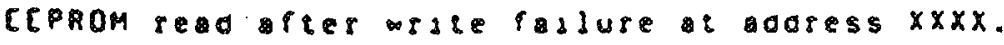

Compuler bus error. unaertaneo restart.

Mes ge numoer 200019 .

Relossolsy rounduo exoonent undertlow.

onclear ostock ocsnter create: inan custent ostack posnter.

onclear abinge stack ocsneer greater inan current machine stack point Unoefineo ocooe.

Sourdous timeou:.

Peode oodnser unoer low imenine stack runnang poodel.

onclear sick unoerflow.

Deorn anoex 800 bo.

Recaro znoex 100 0 19.

Count too odg to siore in recoro.

5puraous indidaldzation. 
APPENDIX 



\section{COUNTING STATISTICS}

\subsection{General}

Radioactive decay is a chance process. For cesium-137 which has a half-life of 30 years, it can be expected that in 30 years one-half of the material will have decayed, but in the next minute exactly which atoms will decay and exactly how many will decay is only by chance. Repeated measurements with the gage will thus most likely result in a different count for each measurement. A typical set of $\$ 2$ such measurements is snown in Fig A-i.

Fig A-2, shows the distribution of these counts. The iwo characteristics of interest are: 1)The average value (also called measure of central tendency or mean) and 2) How wide the counts spread around this average.

Mathmatically the average value is defined as:

$$
\bar{x}=\frac{\Sigma_{x}}{n}
$$

SN 4680

-STATCT-

32- 1998

$3 !-\$ 46 !$

$30-4469$

$29-\$ 269$

$28-4572$

$27-4349$

$26-4360$

$25-4467$

$24-4389$

The width of the spread is defined by a erm called standard deviation.

$29-4407$

$22-\$ 498$

2i-448!

20-4497

$$
s=\sqrt{\frac{\sum(x-\bar{x})^{2}}{n-1}}
$$

$19-4363$

$18-\$ 575$

17- $\$ 513$

$16-4478$

$15-4407$

$14-4390$

$13-4411$

$12-4457$

$11-4463$

$$
s=\sqrt{\frac{n\left(\sum_{x}^{2}\right)-\left(\sum x\right)^{2}}{n(n-1)}}
$$

$10-4871$

8. 4414

8- 4508

7- 4452

$6-441$

5- $\$ 489$

where:

8- 4410

$s=$ standard deviation of the sample

J- 4154

$x=$ count (value of each sample)

20 4879

$\bar{x}=$ average of the sample

1. 442J

The above describes the average value and the standard deviation of a sample from a opulation. They are an approximation to - he true average value and true standard 
$\mu=$ average of the population

$\sigma=$ standard deviation of the population

The distribution from measurement samples of any process can be classified inio expected shapes that have been previously observed. Three are applicable to radioactive decay: Binominal, Poisson and Normal (also called Gaussian).

The Binominal distribution applies when the measured event can take one of two states. Tossing a coin is an obvious case. It can also be applied to a given arom either decaying or not in a time period. It is difficult to deal with computationally.

Since the number of atoms is very large and the expected probability of a decay occuring is very low (source lite in years and measurement time in minutes), we can use the Poisson distribution which is a special case of the binominal distribution for these conditions. A special property of the Poisson distribution is that the expected standard deviation is equal to the squarearoot of the average value.

$$
\sigma=\sqrt{x}
$$

If the sample is large enough we can apo proximate for the standard deviation of the sample.

$$
\delta=\sqrt{\mu}
$$

This is an important relationship. It means that if repeated measurements are raken without moving the gage and the detector electronics are working properly, then the spread of the counts will only be dependent upon. the average count rate. This is in contrast to most measurements where the spread will depend upon the process. Fig $A-3$ shows the diameter of a part turned on a neu lathe while fig Aob shows the same part turned on an old lathe. Both lathes produce a part with the
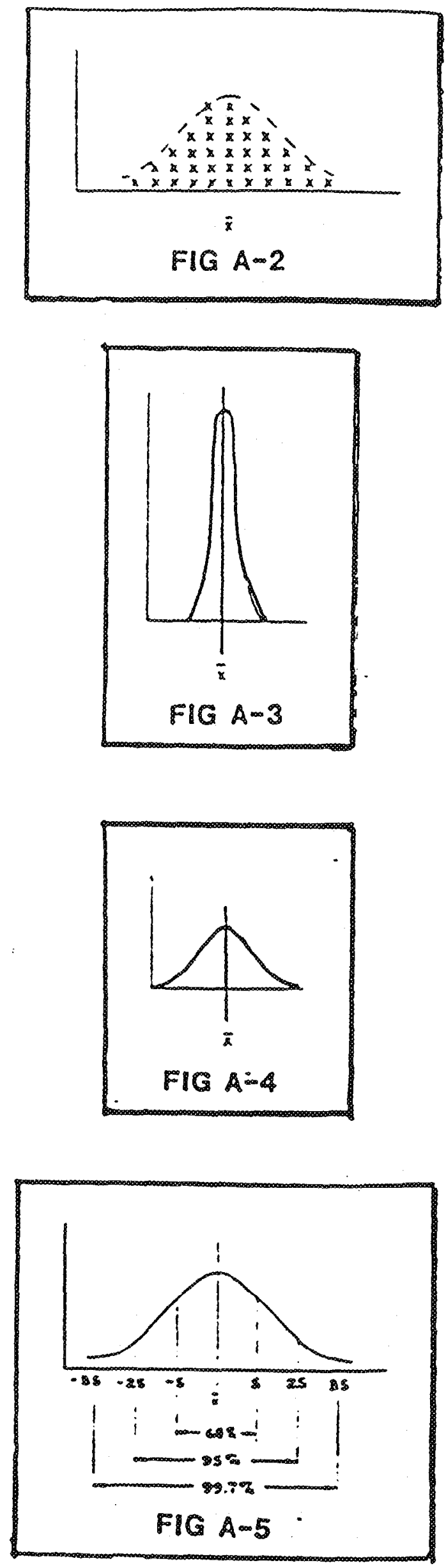
\$ame average diameter but a loose bearing caused the wider spread for papts manutactured on the older lathe.

Poisson distribution applies to discrete measurements e.g. count or no count. Provided the average value is large enough (20 or greater), the Poisson distributions can be approximated by the Normal distribution.

Using the Normal disiribution simplifies things even further. It is a continuous distribution. It is symmetrical about the average, and most importane it can be comolecely described by its average and standard deviation.

As shown in Fig A-5. for a Normal distribution, $68.3 \%$ of all counts will De within one standard deviation, $95.5 \%$ of all counts will be within two standard deviations, and $99.7 \%$ of all counts will be within three standard deviations.

Thus these three distribution models become identical for the case with a small individual success probability but with a large number of trials so that the expected average number of successes is large. This allows the use of the best fearures of each distribution for three statistical situations concerning the gage:

1) Single measurement precision

2) Expected spread of measurements

3) Expected difference between two measurements

\section{Single Measurement Precision}

The expected variation for one standard deviation ( $68.3 \%)$ of a single count can be expressed as a percent error as follows:

$$
\because \text { ERROR }=100 \frac{\sqrt{2}}{2}=100 \frac{1}{\sqrt{2}}
$$

This expression reveals that the only way to improve the count precision (2.9. reduce the percent epror) is to increase the size of $x$ (e.g. the gae mufacture selects components for higher count rate while the gage user counts for a longer period of time).

The following tole demonstrates that minimum of 10,000 counts is required to achieve count precision of 1.0 percent or better $68.3 \%$ of the rime.

$\begin{array}{rccc}\text { cOUNTS } & \text { SR RT } & \begin{array}{c}\text { COUNT } \\ \text { PRECISION } \\ (68.3 \%)\end{array} & \begin{array}{c}\text { COUNT } \\ \text { PRECISION } \\ (95.5 \%)\end{array} \\ 1 & & 100.0 & \\ 10 & 1 & 31.6 & 63.2 \\ 100 & 10 & 10.0 & 20.0 \\ 1.000 & 31.62 & 3.16 & 6.32 \\ 10,000 & 100 & 1.00 & 2.0 \\ 100.000 & 316.22 & .32 & .63\end{array}$


The count precision improves with the square of the count. Thus raking four times the counts improves the count precision by a factor of two.

To provide a consistant frame of reference to the operator, the count displayed in the $D R$ is always an equivalent 16 second count regardless of the time base selected. It is necessary to correct a precision degero mination for other time base selections as follows.

$$
\% \text { ERROR }=100 \frac{1}{\sqrt{x \cdot t / 16}}
$$

where $t$ is the selected time in seconds

Example: A 64 second direct count is taken and displays 3000 . The precision of the count is $P C T=100 /(S Q R(3000 * 64 / 16)$ or $0.913 \%$.

The direct reading is $2.0 \mathrm{gm} / \mathrm{cm}^{3}$. To determine the end measurement precision it is necessary to multiply the count precision by the slape of the calibration curve. Assuming a slope of $0.0416 \mathrm{gm} / \mathrm{cm}^{3}$ per percent. the $2.0 \mathrm{gm} / \mathrm{cm} 3$ reading varies by $+1-0.038 \mathrm{gm} / \mathrm{cm} 368 \%$ of the time representing one standard deviation).

If you take repeat measurenents but move the gage between reading then the standard deviation of that set of readings will include both the source random variation and the variation cise to recpositioning the gage, and thus be larger.

\subsection{Expected spread of measurements}

An accepted quality control procedure for a random counting device is to record a series of 20 to 50 successive counts while keeping all conditiens as constant as possible. By comparing the distribution of this sample of counts with the expected Normal distribution. abnormal amounts of fluction can be detected. Which could indicate malfunctioning of the gage.

The "Chi-squared test" is a quantitative means to make this comparsion. It can be used when a calculator is available to determine the standard deviation of the sample.

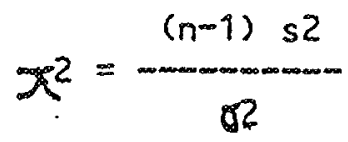

where $x^{2}$ is from the chi-squared tables.

By substituting that the expected standard deviation is equal to the square-root of the average count $(\alpha=\sqrt{x})$, remarranging terms and taking the squaremroot of both sides: 


$$
\int_{(n-1)}^{\times 2}=\frac{s}{\sqrt{x}}
$$

Ideally the ratio on the rignt hand side of this expression should be 1.00. The degree to which this ratio departs from unity is an indicator of the extent to which the measured standard deviation differs from the expected standard deviation.

On the left hand side of the expression, the degree to which $x 2$ differs from $(n-1)$ is a corresponding allowance for the dedarture of the data from the predicted distribution (e.g. We flip a coin ten times and expect five heads and five tails but acceps other distributions for a given sample). Chimsquared distribution tables are found in texts on statistics. The table values deoend upon the degrees of freedom (one less than the number of counis) and the probability that a sample of counts would have a larger value of $\times 2$ than in the table. The $\times 2$ values for $2.5 \%$ and $97.5 \%$ (a $95 \%$ probability range) and 31 degrees of freedom are 17.54 and 48.23 substisuting these value into the left hand side of the expression gives ratio limits between 0.75 and 1.25 for 32 samples and a 95\% probability.

If the patio on the right side is between these limits then there is no reason so suspect the gage is not performing properly. If the ratio is outside these limits then the gage is suspect and further tests are in arder leven a properly working gage will 4 all outside the chi-squared simits $5 \%$ of the times.

If calculator is not available which can easly determine the standard deviation qualitaive thod to comore the observed standard devia tion wish the expected standard deviation is to take a series of 10 couns and determine their ean and the squaremroot of heir mean (guess the squareoroot to 2 digits if not available on the simole calculator). If their distribution is normal then $68.3 \%$ of the readings will be within the ane $+1-$ the square-root of the mean $(e .9 .7$ out of 10$)$. 


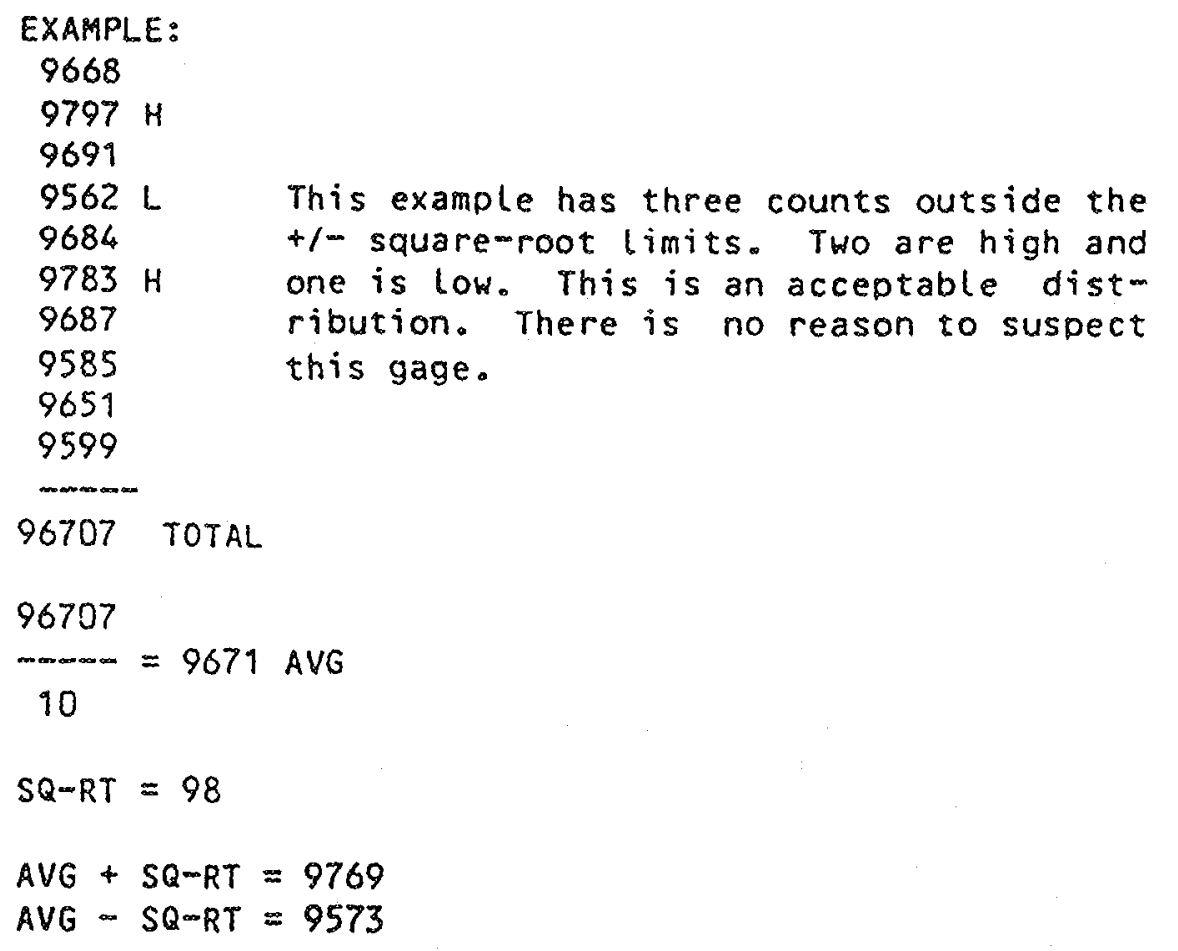

Since this test only involves a sample of ten counts it is not very predictable. Even a properly operating gage will only pass this test one out of four times. If the test fails repeat it to see if any adverse trends exist.

\section{3 expected difference between two readings}

The standard count or some other reference count should be recorded on a regular basis to allow observing if it stays the same or if any adverse trends are present. If enough counts have been used to determined the average and thus also the standard deviation of the population, then the Normal distribution may be used.

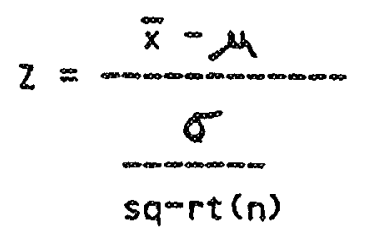

Expressing the $\bar{x}$ value in terms of the $\mu$ value plus a factor of the deviation.

$$
\begin{aligned}
& \bar{x}=\mu+1-k * \infty \\
& z=+1-k * \operatorname{squrt}(n)
\end{aligned}
$$

From the Normal tables, for $95 \%$ confidence, the $Z$ value is 1.96 .

$$
k=+1-\frac{z}{\sqrt{n}}=+1-\frac{1.96}{\sqrt{1}}=+1-1.96
$$


Thus the new reading should be equal to the average of the old reading plus/minus 1.96 times the square root of the old average.

"his is true for the 16 second count which is direct. For another time ase the $K$ term must be reduced by the squareoroot of the count premscaling. e.g. for a 64 second count which is 4 times as long as the direct 16 second count the new reading should be olus/minus 0.98 . A special case is the standard count wnich involves 32 each ( $n=32) 8$ sec ond counts. A new standard count should be equal to the old standard count plus/minus 0.49 times the squaremroot of the old standard count 95 percent of the time.

EXAMPLE:

The average of the daily standard count for the last month is $10,000$. The square-root of this average is 100 . A new standard count ( 32 each at 8 seconds but displayed as 16 seconds) should be between 9,959 and 10,041 ( $95 \%$ probability).

\subsection{TROUQLE SHOOTING}

\section{CONOITION}

Chi patio too high, no change in the average count over previous.

Chi ratio too low with an increase in the average count over previous.

Chi ratio too low no change in the average count.

Chi ratio oK but change in average count.

\section{POSSIBLE CAUSE}

Look for orift in the counts over the measurement time. e.g. the average of the first five counts is significantly different than the average of the last tive counts.

Periodic noise occuring. Possibly an open filter capacitor in the HV power supoly.

Procedure error. Possibly analyzing normalized counts. The siandard deviation must be determined on direct counts.

change in gage geomerry. A change in counting efficiency will be normalized out by ratio technique. A change in gage geomerry must either be coprected or the gage recalibrated. 
One of the features of the SOSOR is to communicate with other computers as a remotely activated device or to download its logged data records to a disk or printer. There are two parts to this process: downloading software, and $R S-232 C$ serial communication hardware.

DCGRLOADING RECOROED DATA

Using the logging feature the gauge can record many records of site readings for recall later. It is extremely convenient if that data can be used in a program that can manipulate the data for the users needs. To get the data from the probe to the computer you may use the PRINT CD feature which stands for PRINT Computer Dump. Computer to computer communication requires a matched standard means of data communication implemented on both ends of the transfer. The gauge is capable of serial communication in an RS232 ASCII format which is standard for many computers and communication packages written to be used on them. One problem of serial communication is that it is not fool-proof and some form of error checking must be preformed on the data to insure that it is valid. The gauge uses a format where at the end of each line that is transmitred the computed checksum of the ASCII values of each character in the line is sent as the last data field. The receiving program must compare this value with the value it computes as the data is being received and send back an appropriate response. This format of communication is styled after ACK and NACK types of communication. The response is either ACK the line was received correctly and it is ACKnowledged or the response is NACK the line was not received correctly and it is Not ACKnowledged. The gauge receives the response and either ransaiss the line again or transmits the next line. The data records received are stored as a file on the current storage medium.

The Drogram specifications that pertain to the gauge are:

RS232 rype serial communication (TXD, RXD, GND).

1 start bit, 8 data bits, no parity, and 2 stop bits.

Baud rates: $190,300,1200,2400,4800,9600$ (programs in basic may not operate at speeds higher than 300 baud).

ACK character ASCII value 6 decimel.

NACK Character ASCII value 21 decimal (any unrecognized character is treated as a NACK character).

checksum computed by ASCII values up to and including the comma before the checksum field.

' $D$ ' is the ASCIX character (value 912 decimal) that will remotely activate the PRINT feature of the gauge.

$C R$ is the ASCII character (value 13 decimal) that will remotely acknowledge the PRINT CD prompt.

Included here are the descriptions and program listings for several types of computers that compose a fairly good cross-section of the microcomputers that are currently available. Even if the computer that you are currently using does not directly correspond to one of the ones listed, there is good chance that with the information provided in the listings and a careful study of the programmers manual for your computer that you could urite a downloading program of your own. The last listing DRINZDMP. BAS will convert the download file from the standard format 
to the format used by the IRRIGATION WATER MANAGEMENT SYStem sotiware from CPN CORP. It will operate as is on most of the microcomputers using variations of MIRCOSOFT BASIC for computers with disk drives.

\section{ISTING \#1}

This version of ORDUMP will operate on most IBM DC's and the ir close compatioles. It has been used on an IBM PC, HEATH/ZENITH 100 or 150, TELEVIDEO 1605, and with the replacement of line number 390 with the one listed below it will also operate on the APPLE MACINTOSH with MICROSOFY BASIC.

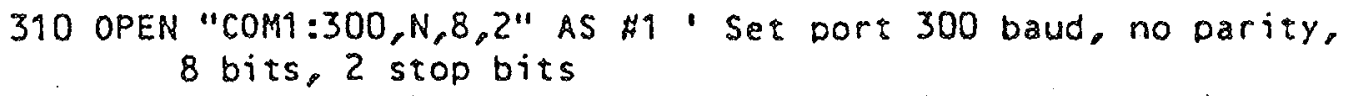

The requirement for this program to work is the inclusion of the OPER "COM1:... statement in the BASIC language used. 


\section{LISTING}

This version of OROUMP was written for a CP/M based microcomputer that uses the Dort method of 110 addressing. It was specifically uritten to operated on a VECTOR GRAPHICS Model 4 as is or the following computers with their associated line modifications.

VECTOR GRAPHICS 3

No changes just use the printer port.

VECTOR GRAPHICS VSX

$1605 T \%=6$ ' Staqus port number

360 OUT ST\%, BHI8 ' Reset the Dort

362 OUT ST\%,8HIL ' set port mode: ( 1 start), 8 data, no parity, 2 stop bits

364 OUT ST\%, $8 H 4 C$ ' set port for transmit and receive

366 OUT 5T\%,\&H15

368 OUT ST\%, RHEA

370 OUT ST\%,8HIT

372 OUT $5 T \%, 8 H 00$

374 OUT $5 T \%, 8 H 93$

376 OUT ST\%, \&HC1

380 OUT $5 T \%$ \& 810

830 OUT ST\%,\&HIO: WHILE (INP(ST\%) AND 4 ) = ZIP\%: WEND ' Wait for eransmitter ready

870 K\% $=1000:$ OUT 5T\%, 8H90: WHILE ((INP(ST\%) AND ONE\%)=2IP\%)

AND $(K \%>Z I P \%): K \%=K \%$ - ONE\%: WEND

970 OUT $\$ T \%, 8 H 10:$ WHILE (INP(ST\%) AND 1) $=2$ IP\%: WEND $\&$ Wait for line feed character

OSA ZEUS

150 DP\% $=21$ data port number

$160 \mathrm{STH}=3$ ' status port number

220 PRINT CHRS(26) - Clear screen

360 OUT. $5 T \%, 8 H 18$ ' Reset the port

362 OUT ST\%, \&HY 4 set port mode; ( $\mathrm{start}$ ), 8 data, no papity, 2 stop bits

366 OUT ST\%, 8 H4C set port for transmit and receive

366 OUT $5 T \%, 8 H 03$

368 OUT ST\%,\&HEI

370 OUT ST\% \&HOS

372 OUT ST\%, \&HEA

374 OUT $5 T \%, 8491$

376 OUT $5 T \%_{8} \$ 100$

378 our 461,8405 - Set to 300 baud

380 OUT 8 H61, 3434

6SS IF PRNTR\% THEN LPRINT CHRS(26) ' Send to printer

830 OUT ST\%, \&H10: WHILE (INP(ST\%) ANO 4) = ZIP\%: WEND 8 Wait for transmicter ready

$870 \mathrm{~K} \%=1000:$ OUT ST\%, BHI0: WHILE ((INP(ST\%) AND ONE\%) =IIP\%) AND (K\% > ZIP\%): K\% $\approx K \%$ - ONE\%: WEND

970 OUT \$T\%, 8 H10: WHILE (INP(ST\%) AND 1) = ZIP\%: WEND ' Wait for line feed character

11S5 IF PRNTR\% YHEN LPRINT CHRS(26) 'DUmp printer file 
This is an assembly language upgrade to listing $\# 2$ that will input dar at speeds up to 9600 baud. The assembly language routine will have to be loaded at 40000 decimal before the basic program is run. The line changes required to implement it with listing $\$ 2$ are:

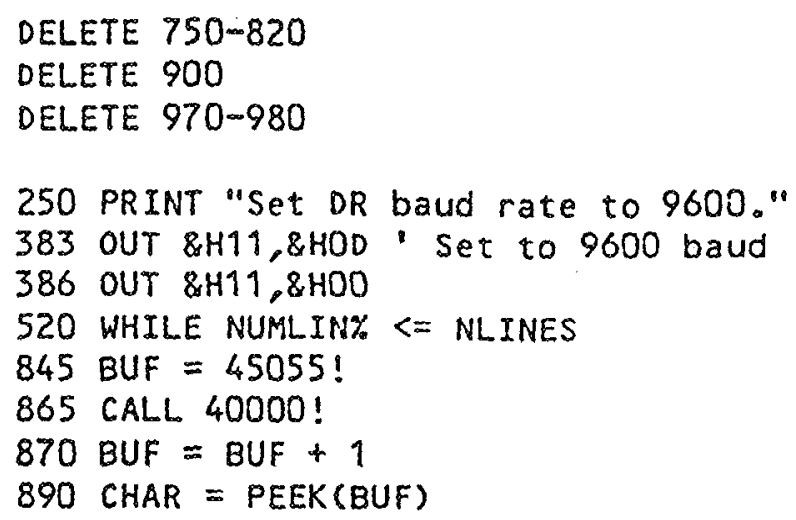

LISTING H4

The special characteristics of the OSBORNE 1 and it's memorymapped I/O that is page flipped with the program memory spauned this intepesting use of the CP/M I/O byte at location 3 to suap the console with the serial port to input the data as though it was keyboard entry. It requires the OSBORNE'S SETUP program to set the configuration of the cort to 300 baud before running the program.

LISTING 45 and $\# 6$

The APPLE II/II+/IIe/and IIC also have special considerations since in the beginning when the APPLE II was first designed there was no such thing as disk drives, serial communications, and printers vailable for microcomputers. The designers thought ahead enough to provide for "plug-in' expansion that would include such things but INTEGER and APPLESOFT BASIC did not provide for direct intepface with them. The result is a two part program in APPLESOFT BASIC and 6502 assembly tan guage that receives the data through a SUPER SERIAL CARD (FrOm APPLE) plugged in a card slot that is pointed to by the variable SLOT in the basic portion line 50 .

Type in the BASIC listing 45 and save it as DRDUMP. Type in the HEXDUMP for listing $\# 6$ by using the following steps:

CALL -151

*300: $A 984 \ldots$

*370: $20^{\circ} 9$ OC FC 60

*BSAVE INPUTDR AAMP,A\$300,LS74 


\section{LISTING}

This program is simular to the others but uses the ROM routines built into the TRS80 MODEL III \& \& to input the data on the serial port. It will run on the MOOEL III with no modifications and it will work on the MODEL \& if it is brought up in MODEL III emulation mode (booted with a MOOEL III disk).

\section{LISTING $\# 8$}

This is the file converter that manipulates the data into the format expected by the IRRIGATION WATER MANAGEMENT program from CPN CORP. It will operate on most computers that use MICROSOFT BASIC for disk drives. 
IOZ32C SERIAL COMAUNICATION HARDWARE

1e $503 D R$ uses the RS-232C industry standard serial communication hod. The 503DR cable connector is a special CPN CORP. configuration nat can be linked to a 25 pin D-type connector on the opposite end of he cable. Most computers will have the DP25S (25 pin D-type sockers) onnector built in although the IBM asynchronous communications card and few others have a DP25P (25 pin D-type pins) connector built in.

ere are a collection of some of the more popular cable configurations: 


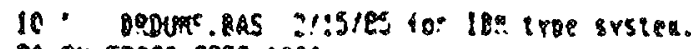

20 OA ERROR G2TO 2000

$30^{\circ}$

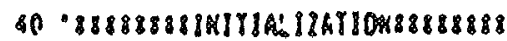

50.

60 AISO $8=$ CMRS 1291

$20 \quad 28 \div 1000$

80 GKSKERS: YESES

90 RAT:: $=6$

100 KAY.S $=21$

$190 \quad 6.8 \div 93$

120 FF8 CHRS (1?)

$130 \quad B K 2=0$

$140^{\circ}$

$150 \cdot 8281$ PROTEDUE 1888

$160^{\circ}$

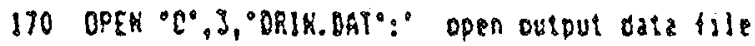

180 PRIKT FFE

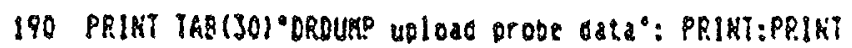

200 PRIKT "Set DR Dawo rate to J000ps."

210 PRIKT 'Connect cable to DR."

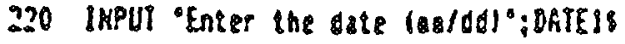

230 PRIHI 19.DATEIS

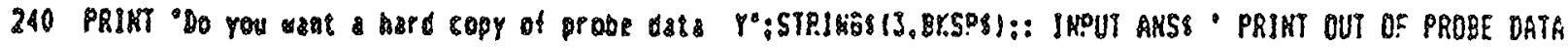

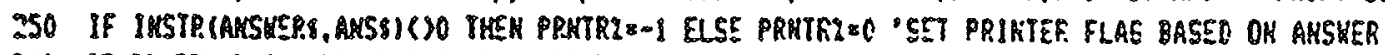

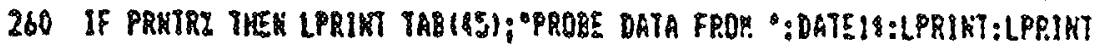

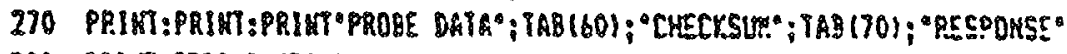

390 PRIKT SIRIKSS $\left.178,{ }^{\circ}\right)$

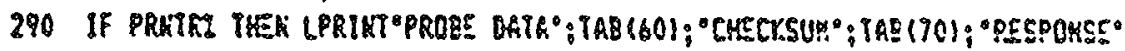

300 IF PRKTRI THEA LPRIMT STRIKES $\left(78, "{ }^{\circ}\right)$

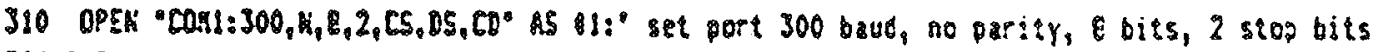

320 - Rezotely actirste PRIKT Co De.

330 PRIKT 11. "O": FOR \& I 10 1000: KEXT: PRIKT 81, "

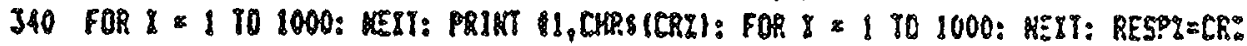

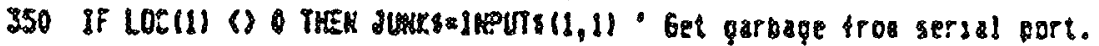

$\$ 606054600^{\circ}$ call fipst line in

370 costo $\$ 50$ PQIn TLIKE

$380^{\circ}$

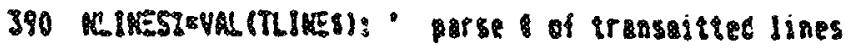

400 PeIkT 8j,TLIKE: - put heager hae in cortout file

$410^{\circ}$

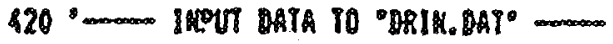

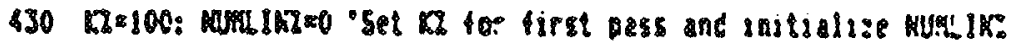

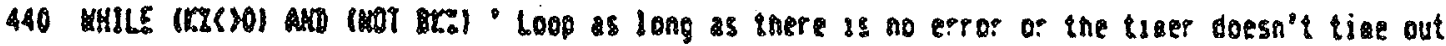

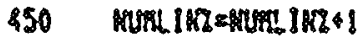

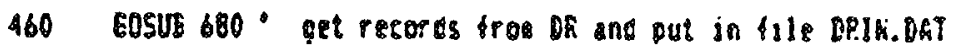

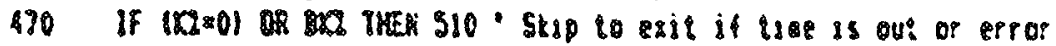

880 PRIRT B3, TLRES

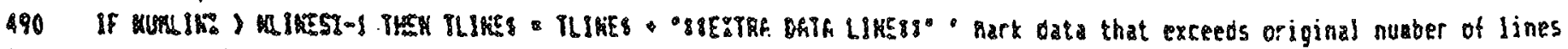
500 COSUE $950^{\circ}$ PQIKT TLINE

310 KE

$520^{\circ}$

53O PRINT IS, CHRS (ACELA);

$580^{\circ}$

550 
- IF PRKTRI THEH LPRIMT FFS ' Qutput \& for atzed

CLOSE 11

CLOSE 13

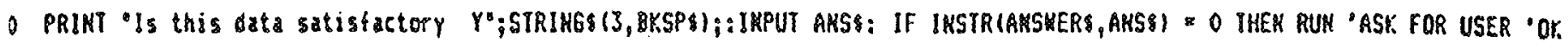

IF BKI THEN EKD' Finish if error has Decured

$\checkmark$ CHAIK 'DRIK2DKP. BAS" ALL' COMVERT DATA STRIKE TO PARSED INFORAKTION.

$\partial$ END

$j$

J ' 881888 SUBRDUTIHESTI1881

0,

J'SUB-D.- IKPUT LIKE -...-

$j \cdot$

) PRINT 11, EHRS (RESPY);

ILINES:-・

CKSUKLEO - reset cksue for nee record

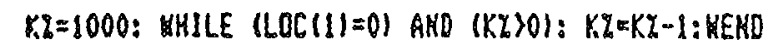

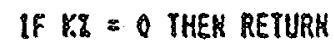

CHARE !NPUTS 11,111

IF ASC(CHARS) 13 THEK GOTO $810^{\circ}$ is it the EKD OF RECORB?

IF IKKEYS $(>\circ$ THEN ERROR

ILIKES=IUIKES+CHARS ' if not, add it to the record string

MURBI 2 ASC(CHARS)

Cxsunz=cKstmatwumg2 ' and record it in the eksur

soro $710^{\circ}$ get next character

1

END OF RECORO Processing

IF LOCIII:0 THEN $820^{\circ}$ WAIT FOR A CHARACTER IN COK-BUFFER

CHARS IKPUTS 11 , III' DISCARD LINE FEED

LASTCHARI ELEM(TLIMES)' length of dats string

LSTCOHKRLELASTCHARI ' initial ize consa pointer

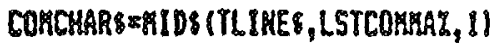

WHILE COKCHARS( $)^{8}:$

CKSUKZ = CKSUKI-ASC (COKCHARI)

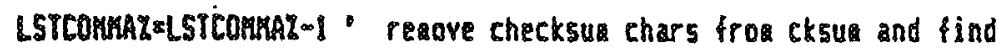

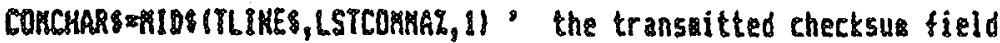

UEND

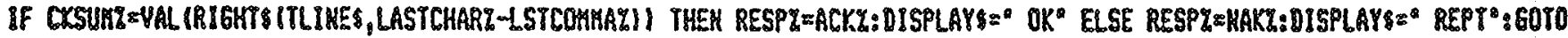

10 - repeat line till right

RETUR日

1.

- PRINI TLIHE

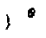

PMIKT ILIME ; TAB 601 ;CKSUKL; TAB 1701 ;RESPL;DISPLAY ' DISPLAY DATA

I IF PRKTRZ THEN LPRINT KLIHES;TAB 1601 ; Cr.SURZ; TAB 1701 ;RESPZ;DISPLAY - PRIKT DATA

RETURK

10 PRIKT "COKKURICATION INTERUPTED': BKI=- : RETURR ' HAKDLE ERROR IKCLUDIKE KEYBOAPO IHTERUPTIOKS 
10 DRPMP. BAS 2/15/ES FOF VECTOY 4 IYPE SYSTERS.

20 OK ERROK 60908870

30 - IRAKSCER FROR PROE: IO FILL DR.JM.DET

$40^{\circ}$

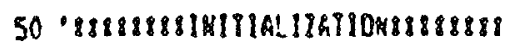

$60 \quad 1.2 \times 1000$

70 ANSKERS $x$ - VESYES

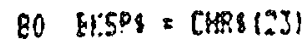

90 Aar: $=6$

$100 \quad \operatorname{RaK}:=21$

$110 \quad \mathrm{CK}=13$

120 ONEI $=1$

130 THOZ $=2$

$140 \quad 218 \mathrm{P}=6$. nuberigal constants

150 DPI \& 4:' dats Dort nuaber

$160 \mathrm{SIS}=3 \mathrm{I}^{\circ}$ status port number

$170 \mathrm{BN}=0$

$180^{\circ}$

190.8888 PROCEDURE 2881

$200^{\circ}$

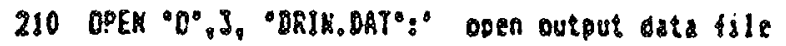

220 PRIKT CHRs (4):

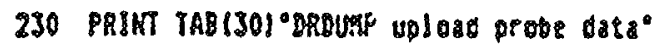

240 PSIKT: PRINT: PRIKT

250 PRIM "Ses DR baut rate to 300."

260 PRIRT "Connect cable to DR."

270 INPUT "Enter the date (as/68):

280 PRIIT 13, DATELS

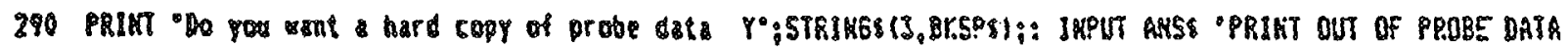

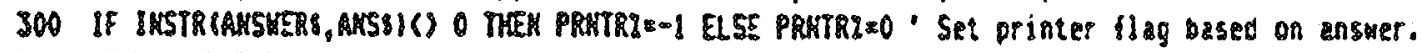

J10 If PRKRT IKEK LPRIKT TAB IS5I; PROBE DATA FROM "DRTESS: LPRIKT:LPRIKT

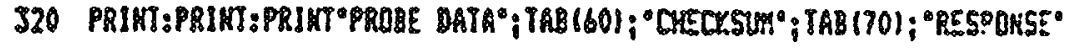

JJo PRIKT STR!HEs $\left.178,88^{\circ}\right)$

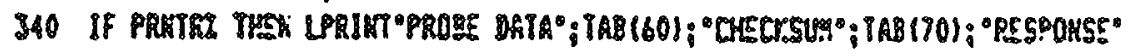

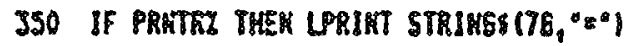

360 OUT 5T\&, \&H40: - reset the ont

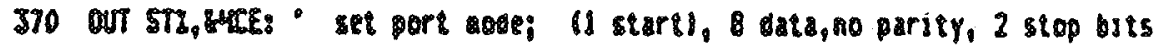

380 OVI 5T, th25: - set port for tr ansiat and recejve

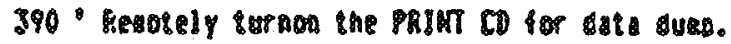

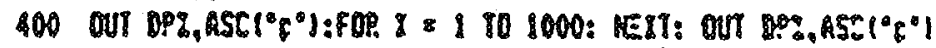

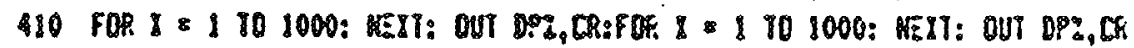

$420^{\circ}$

130. Inove nemeer d8as

$44069548250^{\circ}$ sall farst lane in

450 GLSUE $1220^{\circ}$ PRIKT ILIKE

$460^{\circ}$

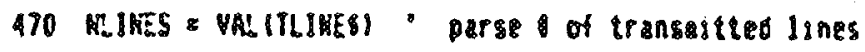

460 Phthi 83. ILIKEg. Dut hez6er line in outpest fille

$490^{\circ}$

$500^{\circ}$ 
i10 KI $\approx$ 100: MUTLIKZ $=0^{\circ}$ Set K\% for first pass and initialize NURLIKI

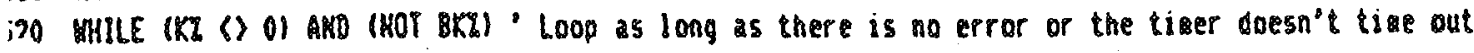
MUXL INZ $=$ GURLINZ +1

140 GOSUB $830^{\circ}$ get all the records froe the OR and put the in the file BRIN.DAT

i50 If IKI $=01$ OR BK\% THEN $590^{\circ}$ SKip to exit loop if tise is out or error

i60 PRIKT 3 , RLIMES

i70

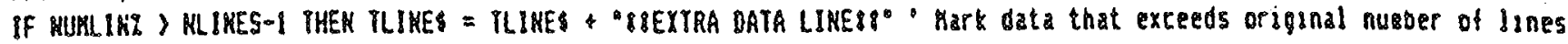
GOSUB $1120^{\circ}$ PRIKT TLINE

I90 WEKD

$300^{\circ}$

S10 OUT DPY, ACKL:' Do one eore ACK to allox OR to Sinish

$\$ 20^{\circ}$

$\$ 30^{\circ}$

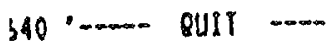

650 IF PRMTRZ IHER LPPIKI FF' ' Output a for steed

660 CLOSE IJ

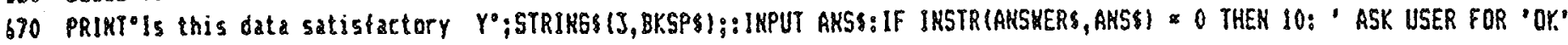

680 If BKI INEK $700^{\circ}$ Skip converting data if error has occured

690 CKRIK "ORIK2DKP.BAS", ALL ' Convert data string to parsed inforation.

700 END

$110^{\circ}$

$720 \cdot 881848$ SURROUTIKESI 6 เ 18

$730^{\circ}$

740. SU8 - Input first line -.am

750 - LIMES 860 THRU 920 KAVE TIKE CRITICAL CODE.

$760^{\circ}$ LIKE 8602) WAIT FOR CHARACTER TO BE RECEIVED ITIME HAIT

290 - LINE 870 3 CHECK FOR OUER-RUN STATUS

- LIRE BBOz $\Rightarrow$ get CHARATER

790 - LIKE B90 $>$ RETURN IF TIKER RAY OUT

B00 - UIME 9003) IS IT 'CR' THES END OF RECORD

Q10 LIME 910 $\Rightarrow$ CHECY. FOR KEYBOARD IKTERUPTION

820 - LIME 920 $\Rightarrow$ MAKE ILIMES, AND CHECXSUK. GO GET MEXT CHARACTER

830 WHILE IINO(STI) AKD 11 = LIPI: MEND " Hait for transuitter ready

810 OUI DPZ,RESPL" . Send response to OR

850 ILIME $=\cdots$ - Clear line record buffer

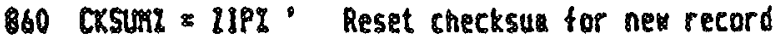

870 K \& 1000: WHILE (IINP (STI) AND THOZ) ะZIPZ) AND (KZ > IIPZ): KZ = KZ - OKEZ: KEKD

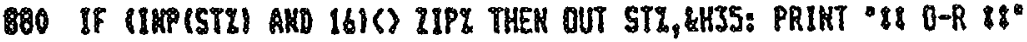

Q90 CHAR $\approx$ IMP(DPL)

900 If $K Z=O$ IHEK RETURK

910 If CHAR $*$ CR THEN 970

920 IF IKKEYS (S " THEH ERROR

930 PLIMES = ILIKE + CHRS (CHAR): CXSUKL = CKSUKL + CHAR: 6OTO 870

$940^{\circ}$

950 - EKD OF RECORD processing

$960^{\circ}$

970 WHLL IJKP ISTW AKD 2IxIIP\%: WEKO' wait for line feed char

980 CKAR = IKP(DPY): - get the line feed

$\$ 90$ LASTCHAR = LEM(ICIMEs): " get length of data string

8000 LSTCOKA = LASTCHAR: ' initialize cona pointer

8010 COKS $=$ HIDS (TLIKES, LSTCOKKA, OREL) 


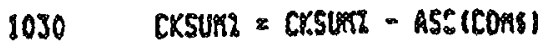

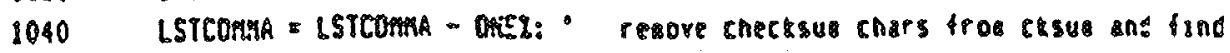

1050 COKS a RIDS(TLIKES.LSTCORA, OHEL): - ine ir anssitied cnecrsse fielo

1060 MEKD

$1070^{\circ}$

$1080^{\circ}$ Kesponse is ACr. if shecksur is correct, else Ka!. and rebest untsl get at racht

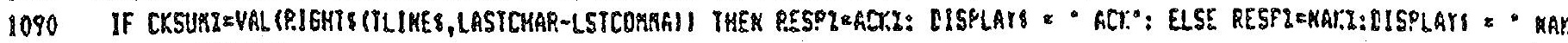
: GOSUE 1120: 60T0 740

1100 P.ETUPA

$1110^{\circ}$

1120 PRINT TLIKE

$1130^{\circ}$

1140 PRIKT TLIKE\&;TAE1801:CISSUKZ; TAB1701; RESPZ; LISPLAYS - DISPLAY DATK

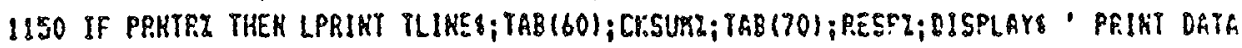

1160 RETURM

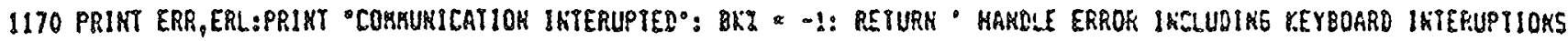

TYPE DRLIN.ASK

I8818 PGK: BRLLIN.ASK 88888888985030498888838

i

iASY SURROUTIKE FOR DATA IKPUT FRAK DR

iPGK START at 90000D, gC40H

; DATA STORAGE START AT 45056D, BOGOH

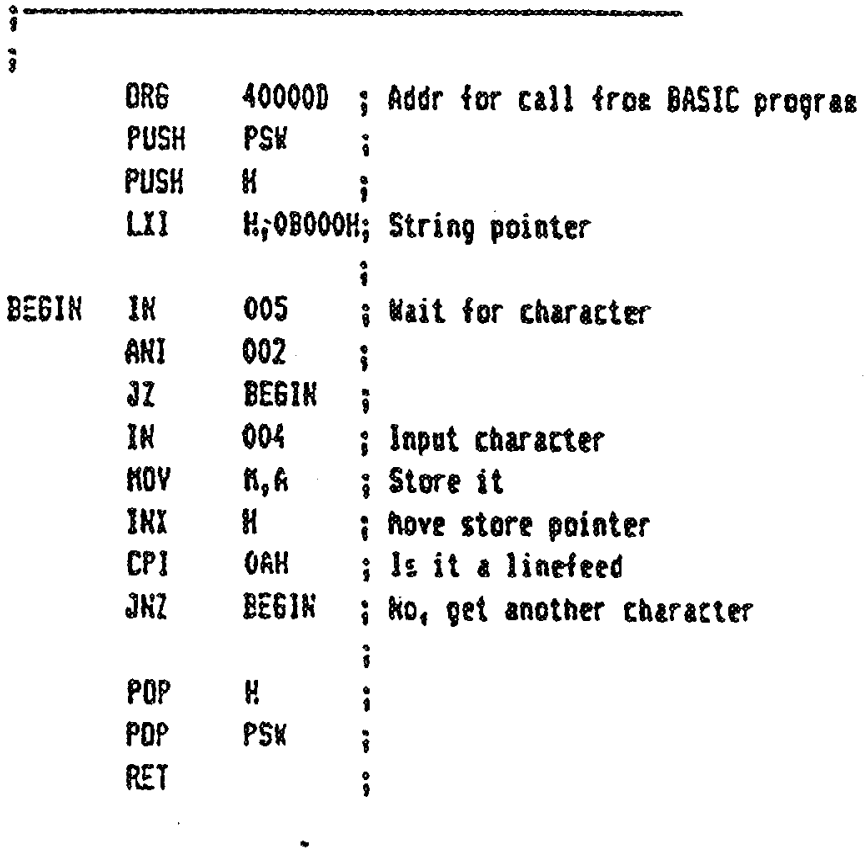


- - 5038R 10 DSBORAE UPLOADER 2/85/85

IV ERROR GOTO 900

iv lOPORT\&\&

10 IOKORKZ :PEEK (1OPORT:

iO 10COHKI:\&HA!

SO ACr $\$ \times$ CHRS $(6)$

10 HACX $\times$ CHR 1211

30 CRSECHRS (IS)

10 BKSP $=$ =CHRS (8)

100 AKSHERS $=$ " YeSYES"

110 IIPT $=0:$ OKEI $=1: T \% 0 I=$ ?

120 BKI:0: ERRFLAE? =0

$130^{\circ}$

$140^{\circ}$ SETUP PORT AKD PROKPT USER

$150^{\circ}$

160 OPEK ${ }^{\circ}, 3^{\circ} 3^{\circ}$ DRIN. DAT" - OPEK OUTPUT DATA FILE

170 PRIKT CURS (26) ' CLEAR IHE SCREEK

180 PRIKT TABIISI QRRDUKP upload probe dat ":PRIKT:PRIKT

190 PhINT "Set or baud rate to soobas."

200 brikt "Connect the cable to the OR."

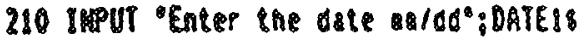

220 PRIMT OS,DATEIS

230 PRIKT:PRINT

260 PAIRT "PROBE DATA":TAZ(45): "RESPOHSE"

250 PRIKT STRIMGS152. $-\circ)$

9ho - Rezetedy actavate PRIKT CD on BR.

OOKE IOPOAT, 10CORRL: PRIKT "P":FOR \& \& I TO 1000: KEXT: PRIKT "P"

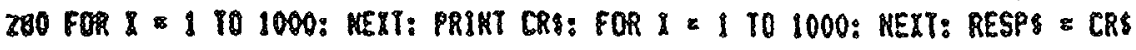

290 suaksalukEY ' Collect garbage off serial port.

$300^{\circ}$

$\$ 10^{\circ}-1$ IRPVI DATA TO "DRIK. BRT"

$320^{\circ}$

350 WHILE \& 20 - GET RECORSS TIU TIREOUT

$\$ 40$ SOSUS $540^{\circ}$ GET ALL THE RECORDS FROK IHE RR ARD PUT THEN IN IHE FILE DRIK.DAT

350 If 2 \& 1 THEK $380^{\circ}$ CHECX. FOP IIKEOUT

360 PRIMT 13, ILIME

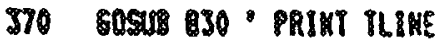

380 MEKD

$390^{\circ}$

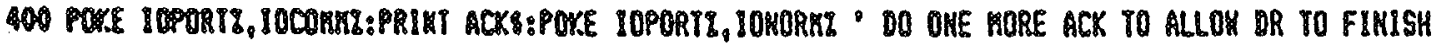

$\$ 10^{\circ}$

$420^{\circ}$

$430^{\circ}$ QuII

480 CLOSE 13

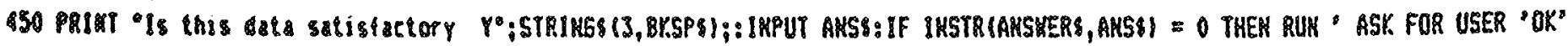
460 IF ERRFLAGS THEN EMO

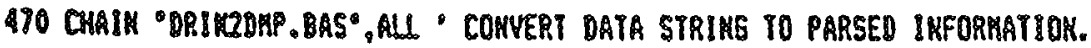

480 EKD

$890^{\circ}$

$500^{\circ}$

IKPUT SU8ROUTIKES 
O REM DRDUMF $\$ / 6 / 85$

W/ SUPER SERIAL CARD

10 FEM

:O FEM INITIALIZATION

O FIEM

5 FIS $=6:$ FEM SET FESFONSE DEFAULT

6 DIM TL\$ (279): REM MAX \# OF RECOFDS 279

O SLOT $=3:$ FEM SLOT \# OF SSC

$O$ DKS $=$ CHR\$ (4): FEM DISK COMMAND

5 GOSUE 1000

O $\mathrm{CM}=$ CHF $\$$ (1): FEM SSC COMMAND

$O$ PRINT DK\$: "FEH":SLOT: REM ACCESS SEFIIAL CAFD

O FFINT CM\$:"

00 PRINT CM\$:"4 DATA": FEM 8 DATA EITS. 2 STOP EITS

10 FFIINT CM\$: "O FARITY": FEM NO FAFITY

20 PRINT CM\$: "LF DISABLE": REM NO AUTO LINE FEEDS

21 FFINT CM\$ "ECHO ENAELE": FIEM FRINT TO SCREEN

22 FRINT CM\$ "MASK ENABLE": FEM MASK OUT IN COMING LINEFEEDS

25 FRINT CM\$"ZAF": RIEM DISAELE COMMAND CHAFACTERS

SO FRINT DK\$: "PR\$O": REM RESET TO SCREEN

40 RIEM

5O FIEM

SO REM

70 HOME

30 HTAB 7: FFINT "DFDUMF UFLOAD FFOEE DATA"

70 PRINT : PRINT

30 FFINT "SET DR EAUD FIATE TO SOO EFS."

10 PRINT "CONNECT THE CARLE TO DF."

20 INFUT "ENTER DATE $=>$ "DT $\$$

SO PRINT : FRINT "DATA": HTAE \$Z: FRINT "RESPONSE": PRINT

10 FOKE \$4.9: REM SET SCROLLING WINDOW

37 FEM

78 FIEM STAFT DUMFING DATA

39 REM

10 FRINT DK" "FFI": SLOT: PFINT DKS"INA" SLOT

14 REM TURN ON PRINT CD REMOTELY

15 FFINT CHFS (112): FOF $X=1$ TO 1000: NEXT: FFINT CHR\$

12): FOR $X=1$ TO 1000: NEXT: PRINT CHR (13): FOR $X$ :

TO 1000: NEXT: FFINT CHRS (1\$): FOR $X=1$ TO $300: \mathrm{NEXT}$

$16 \mathrm{~L}=0:$ \& INPUT TL\$(L): GOSUE 1500: IF RS 21 THEN FRINT

UHF\$ (KS): : GOTO SO6: FEM GET FIFIST LINE

17 FOR $L=1$ TO VAL $\langle T L \$(0)\}-1$

18 FRINT CHR\$ (FS): REM SEND RESPONSE

$O$ \& INPUT TL\$(L): REM GET DATA FFOM PFOBE

:O GOSUB 15OQ: FEM COMPUTE CHECKSUM \& RESPONSE

:S IF FS = 21 THEN 508: REM IF NAK: GET AGAIN

:5 NEXT

i6 FFINT CHF' (b): FEM TURN OFF FFOEE 7 PRINT DK\$ "PR\#O": PFINT DK\$ IN\#O": REM RETURN APPLE TO
IFMAL

:9 GOSUR 5000: FEM WFITE DATA TO DISK

9 FEMT : FND 
000 RIEM

ICSIO F.FINT DH "ELOAD INFUTDF.AMF": FIEM GET MMFEFSAND FIOUTINE TO INEUT SEFIIA: DOATA

IOSO FFINT DI: "ELOAD INFUTDF. AMF."

MGO FOHE 191:.76: FOIE 1014.Q: FOIE 1O1S.: FEM FOINT:

CTOF TO FAEE $\$ O O O$ (708 DECIMAL)

$105 \%$ FIETLIFIN

$1 \triangle 57$ FIEM

1496 FEM COMFUTE CHECKSUM \& DETEFMINE FESFONSE

1499 FIEM

1500 CK $=0:$ FOF $X=1$ TO LEN $(T L \&(L)): C l:=C I:$ ASE ( MIDS.

(TL (L) .X.1)): NEXT

1509 FIEM LOOY FOF LAST COMMA

ISIC FOF LK = LEN (TLY (L)) TO OSTEF - 1

15 . IF MIDS (TL\&(L).LK.1) $=$ " "THEN CS = VAL ( FIIGHTS (TL\$(L).

LEN (TLS (L)) - LKS) :LK: = G: EOTO :ESG

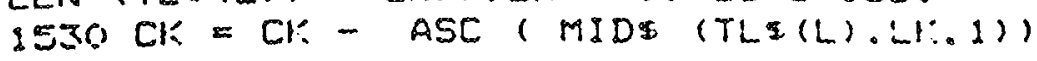

1550 NEXT

1559 FEM IF CHECISUMS MATCH SEND AN ACI:

1560 IF CH: $=$ CS THEN FIS $=0$ : GOSLIE 2010

1569 FEM IF CHECI:SUMS DON'T MATCH SEND A NAY:

1570 IF CK < > CS THEN FIS $21:$ GJSUE 2100

1580 RIETURN

1997 REM

1998 FEM SEND ACI: TO SCKEEN

1999 FIEM

$2000 \mathrm{CH}=$ FEEl: 1401 \& FEEIS 161 : 250

$3010 \mathrm{CH} \mathrm{CH} *=7$

2011 POKE CH, ASC ("A") $\$ 28$

9012 POKE CH \& 1. ASC ("C") +

123 FOKE CH * 2 . ASE ("K") + 128

2020 CALL $\% .96$

2030 RETUKN

2097 REM

2098 KEM SEND NAL: TO SCREEN

2099 REM

$2100 \mathrm{CH}=$ PEEI $(40)+$ FEEK $(41) \times 256$

$2110 \mathrm{CH}=\mathrm{CH}+57$

2111 FOIEE CH, ASC ("N") * 128

2112 POKE CH * 1. ASC ("A") + 128

2115 FOHE CH + 2. ASE ("li") + 128

2120 CALL - 926

2130 FETURN

4997 REM

4998 REM WFITE DATA TO DISI: FILE DUMF.DATA

4999 REM

5000 FRINT "WF:TING DATA TO DISK..."

SCOE PRINT DK "OPEN DUMP. DATA"

SOIO FFINT DK "WRITE DUMF.DATA"

SOIS FRINT DT\$

$\$ 020$ FOF $X$ O TO VAL (TLE(0)) - 1: FFIINT TLE(X): NEXT

50:0 FFINT DK "CLOSE"

$\$ 040$ RETURN 
WOFKS WITH AFFLE II:S

THAT HAVE A SUPEFImSERIAL *

CAFD AND IN THE 40 COL * MODE ONLY.

BY RANDY ANGLE FOF:

CFN COFF.

IN

GDEUFS $=\$ D 5 \$ 9$

SYNCHF: = \$DECO

PTRGET $=$ \$DFE3

GETSFA = \$E4E2

MOVSTR $=$ \$ESE2

CLFIEDL = \$FC9C

RDCHAR $=$ \$FDIS

COUT1 $=$ \$FDFO

BELL $=\quad F F S A$

LENINS $=\$ F D$

FRETOF $\approx$ \$SF

VARPNT $=\$ B \Xi$

INPTOK $=\$ \$ 4$

INVFLG $=\$ \$ 2$

OFE $\$ 0 \$ 00$

LDA HNFTOK

JSR SYNCHR

JSFI FTRGET

LDX $\$ 00$

JSF NXTCHAF

STX LENINS

JSR GDEUFS

LDA LENINS

JSF GETSFA

LDX \#\$OO

LDY \#\$2

JSR MOVSTR

LDY \#\$OO

LDA LENINS

STA (VAFFNT), Y

INY

LDA FRETOF

STA (VARPNT), Y

INY

LDA FRETOP+ $d$

STA (VAFFNT) :Y

RTS

NOTCF:

LDA INUFLG 


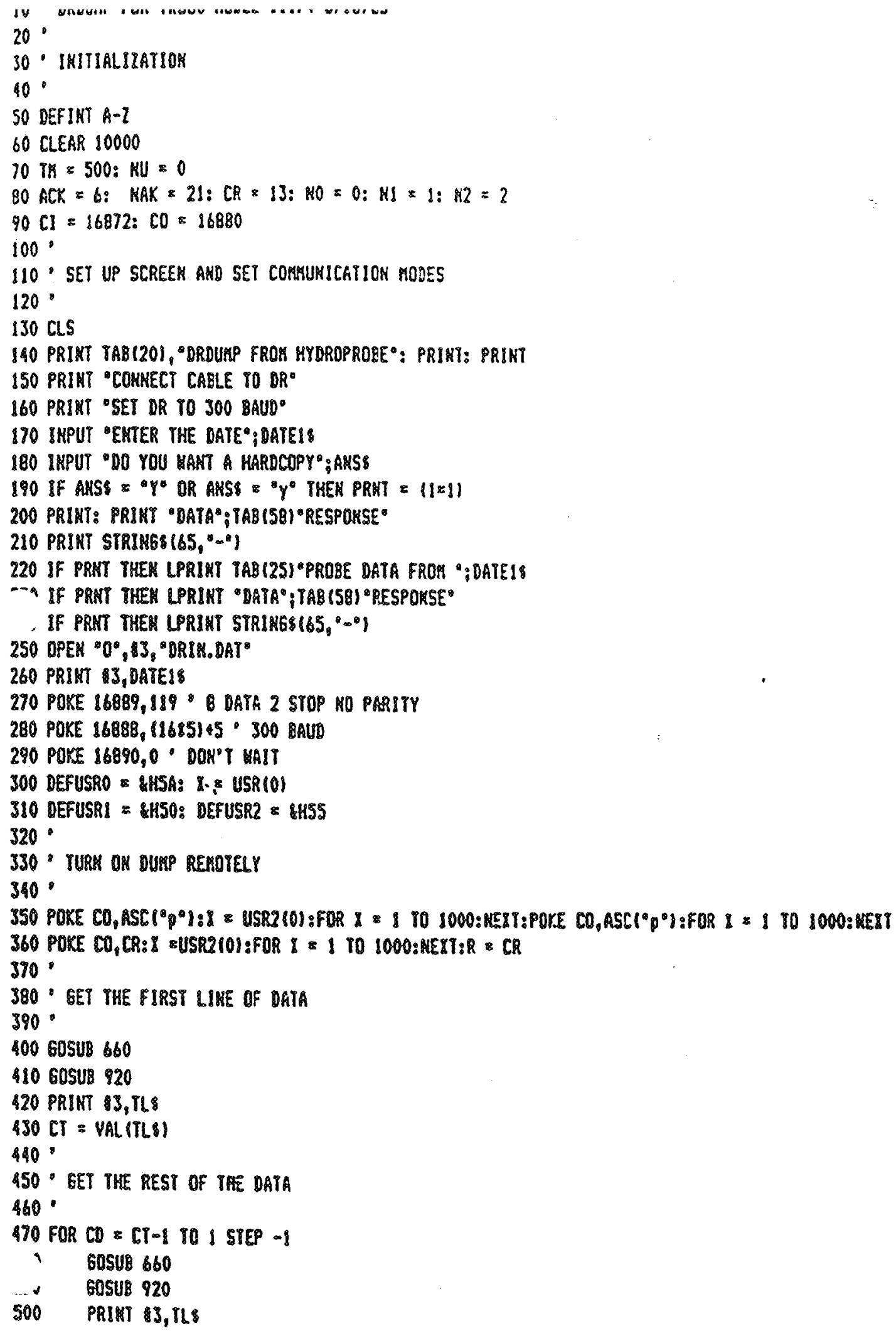


510 K:II

¿20 POKE CC, ACT.

$530 \mathrm{I}=4582(0)$

$540^{\circ}$

550 - CLOSE FILES RME QUTT

$580^{\circ}$

S70 CLOSE BJ

580 IF PRKT THEK LPRIKT CHRS (12)

S9O PRIAT "IS THIS DATG SATISFACTORY;

600 ANS $~=1$ 1KI:EY: IF AKS $=$ THEN 600 ELSE PRINT AKS

610 IF AKSS $(2)^{\circ} Y$ " AKD AMSS $\langle>$ " $Y$ " THEN 10

620 END

$630^{\circ}$.

640 - DOWNLOAD DRTA RECORD OKE LIKE AT A TIME

$650^{\circ}$

660 POKE CO, R

$670 x=45 R 2601$

$680 \mathrm{rLS}={ }^{80}$

$690 \mathrm{KU}=0$

$900 \mathrm{CK}=\mathrm{NO}$

$710 x=$ USR1 10$):$ CK $\approx$ PEEK(CI)

720 IF CN $=0$ THEN $\mathrm{NU}=\mathrm{KU}+1$

730 IF NU > TK THEN NU \& O: R \& NAK: GOSUB 920: 6070660

740 If $\mathrm{CH}=06070710$

750 IF CN $=$ CR $6070 \$ 20$

$760 \mathrm{TLS}=\mathrm{ILS}+\mathrm{CHRS}$ (CN)

$770 \mathrm{CK} \approx \mathrm{CK}+\mathrm{CH}$

7806070910

$790^{\circ}$

BO0 - CORPUTE CKECKSUA FIKD RESPONSE

$B 10^{\circ}$

220 \& USRI 101: CN PEEYICII: IF CK $=0$ 60TO 820

ESC LC $\approx$ LERTLS)

$840 \mathrm{CP}=\mathrm{LC}$

QSE CAS $=$ MIDS (TL, , CP, KL)

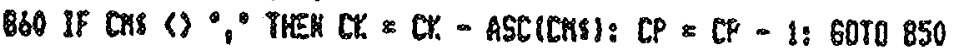

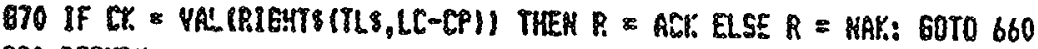

980 RETURA

890

900 PRIMT DATA RECORD

$910^{\circ}$

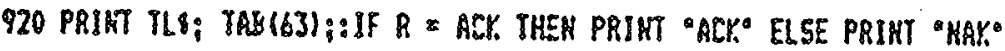

930 IF PRAT THEN LPRIKT ILS;TAB(63);:IF $R$ = ACK THEN LPRIKT "ACK" ELSE LPRIHT "KAK"

940 RETURK 
nT Y.DY(100), DP(100)

1. PROCEDURE 2818

COHYERT DRIK. DAT YO DRDUMP.DAT

OPEN "I: $3^{\circ} \cdot$ DRIN.DAT" open probe into tile

IHEUT 13, DATEIS

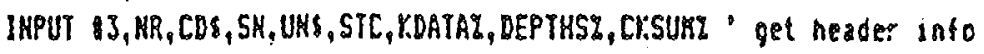
DASHI $=$ IKSTR (CDS, $"-0)$ ' FIKD VEPSION

IF DASHI $=0$ THEK LKST $=(1=1)$ ELSE LKS\% $=(1=2)$ ' SET LIKES NUKBERS FLAG FOR INPUT

IF LMS\% THEN RUKCALSL $=9$ ELSE RUKCALSZ $=17$ - SET KUKBER OF CALIBRATIONS,

FOR $12=2$ YO NUKCALSZ

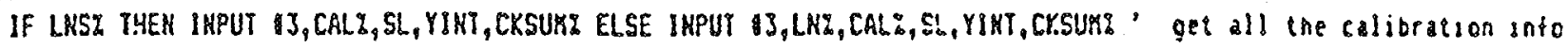
NEXT

OPEN $0^{\circ}, 2,{ }^{\circ}$ DRDUMP.DAT" open the output file

PRIKT 12, DATEIS

PRINT 2, DEPTHSZ", "KDATAZ-1 " write of data records, of depths per record

WHILE HOT EOF(§) " transter info

IF LKSI THEN INPUT 13, 10\%, CALI ELSE IHPUT 13,LK\%, 10\%, CALI

FOR IY KDATAL TO I STEP -1

IHPUT 13, KDY(IZ) ' get all tey fields

NEXT

FOR I $X=$ =DEPTHSY TO 1 STEP -1

INPUT 3, DP(1Y)' get the depth radings

MEXT

IMPUT 13, CKSUK! ' get the checksus

FARHZIHT(IOL/100) " parse the far

FLDI=1DY-(1008FaRMY) parse the field

SITEI = KDO (XDATAL) " get the site

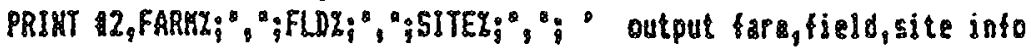

FOR SY=1 TO KDATAL -

PRIMT 2, KOI(IZ):" :

MEXT

FQR $1 Z=1$ TO DEPTHSY

PRIKT 2,DP(IZ);";";' output depth readings

REXI

PRINT 2, Gx.suk\%" output checksuz (end of record)

\section{WEND}

CLOSE

RUK "DRYORK1" - OR RUK YHATEVER PROGRAY YOU HISH

ExD 


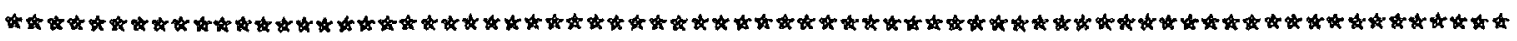
CABLE, GENERAL PURPOSE DR5O3 CONN. CABLE RS232 conn. DP25S

\begin{tabular}{|c|c|c|c|c|}
\hline \multirow{2}{*}{\multicolumn{2}{|c|}{ - }} & \multirow{2}{*}{$-\infty$} & \\
\hline & & & 1 & PROTECTIVE GROUND \\
\hline SERIAL INPUT & 4 & $<-\infty+\infty \infty-\infty$ BLU $-\infty-\infty+\infty$ & 2 & TXD \\
\hline SERIAL OUTPUT & 3 & $-\infty+\infty)$ GRN & 3 & $R \times D$ \\
\hline ENABLE & 7 & $<-\infty-\infty$ YEL $-\infty-\infty-$ & 4 & REQUEST TO SEND \\
\hline$+10 V$ & 1 & 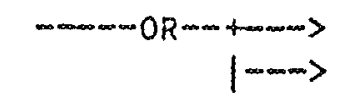 & $\begin{array}{l}5 \\
6\end{array}$ & $\begin{array}{l}\text { CLEAR TO SEND } \\
\text { DATA SET READY }\end{array}$ \\
\hline GROUND & 2 & $\langle-m-\infty \mathrm{BL} K-\infty-\infty \times m-\infty\rangle$ & 7 & GROUND \\
\hline
\end{tabular}

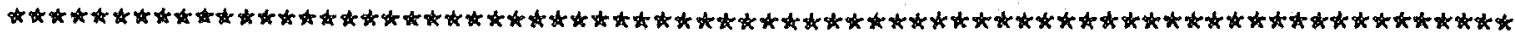
CABLE, GENERAL PURPOSE DRSO3 CONN.

CABLE
RS232 conn. DP25P

\begin{tabular}{|c|c|c|c|c|}
\hline & & & 1 & PROTECTIVE GROUND \\
\hline SERIAL INPUT & 4 & 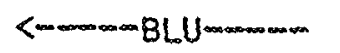 & 2 & $T X D$ \\
\hline SERIAL OUTPUT & 3 & - GRN $-\infty$ & 3 & $R \times D$ \\
\hline ENABLE & 7 & $<-\infty-\infty-Y E L-\infty$ & 4 & REQUEST TO SEND \\
\hline$+10 v$ & 9 & 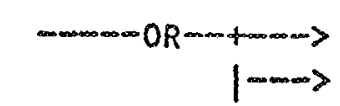 & $\begin{array}{l}5 \\
6\end{array}$ & $\begin{array}{l}\text { CLEAR TO SEND } \\
\text { DATA SET READY }\end{array}$ \\
\hline GROUND & 2 & $\langle\infty-\infty,->$ & 7 & GROUND \\
\hline
\end{tabular}

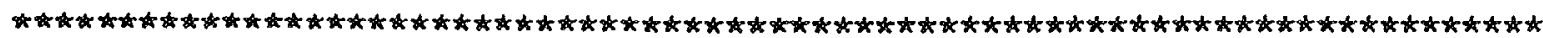

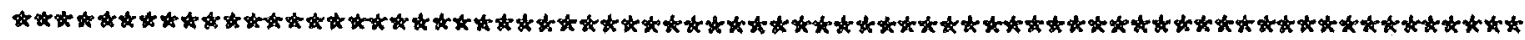
CABLE, VECTOR GRAPHICS $4, J 1$ MODEM CONNECTOR, 300 BAUD ORSO3 CONN. CABLE

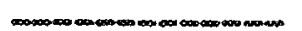

RS232 conn. DP25P

1 PROTECTIVE GROUND

SERIAL INPUT

SERIAL OUTPUT

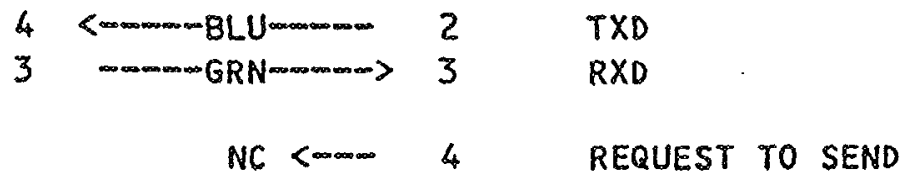

$+10 \mathrm{~V}$

1

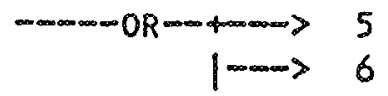

GROUND
CLEAR TO SEND

DATA SET READY

GROUND

DATA TERMINAL READY 


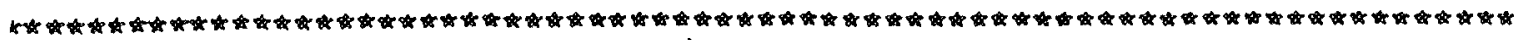

3LE. VECTOR GRAPHICS 3, J2 PRINTER CONNECTOR, 300 BAUD

...j03 conn.

CABLE

RS232 CONn. DP2SP

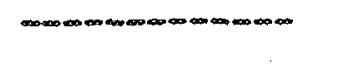

1 PROTECTIVE GROUND

SERIAL OUTPUT

SERIAL. INPUT

$3-\infty-a n-G R N-m \infty-\infty \infty \infty\rangle$

PROTECTIVE GROUND

$+10 \mathrm{~V}$

$4<m-m-B L U-m-m$

RXD

$T \times D$

+10

1

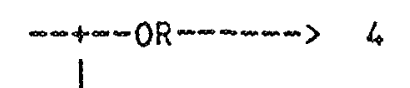

CLEAR TO SEND

NC $<-\infty \quad 5$

REQUEST TO SEND

NC $<-\infty \infty \infty$

DATA TERMINAL REAOY

GROUND

2

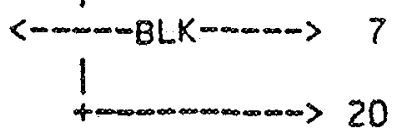

GROUND

DATA SET READY

ENABLE

7 < - $-m-Y E L$ NC

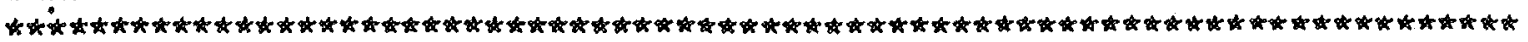

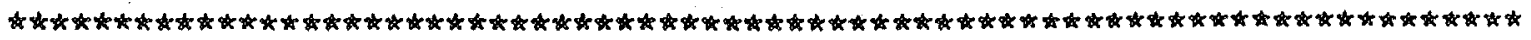

CABLE, DOCAT MODEM, 300 BAUD

DR503 CONn.

CABLE

RS232 conn. DP2SP

- RIAL OUTPUT

SERIAL INPUT

3

3 - 3 -

$4<-B$ -

TXD

RXD

NC $<-\infty \quad 5 \quad$ REQUEST TO SEND

NC $<$ DATA SET READY

GROUND

$2<m$ GROUND

NC $<-\infty-8$ CARRIER DETECT

$+90 \mathrm{~V}$

ENABLE

$1-O R->N C$

7 <

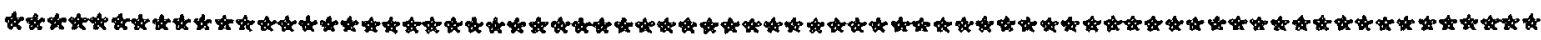




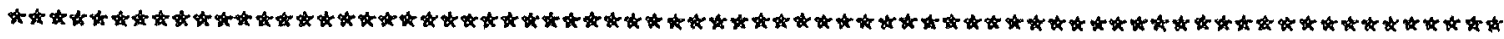

CABLE, SIGNALMAN MODEM, 300 BAUD

DRSO3 CONN. CABLE

RS232 conn. OP25S

SERIAL OUTPUT

SERIAL INPUT

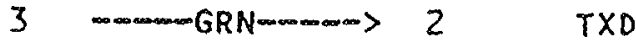

$$
\begin{aligned}
& 4<-\infty-\infty m B L U-m \text { RXo } 3 \\
& \text { NC }<\cdots \infty \quad 5 \quad \text { REQUEST TO SEND } \\
& \text { NC }-\cdots \quad \text { D DATA SET READY }
\end{aligned}
$$

GROUND

$2\langle-a-B$ BLK $-m \rightarrow->\quad$ GROUND

NC $<-\infty$. CARRIER DETECT

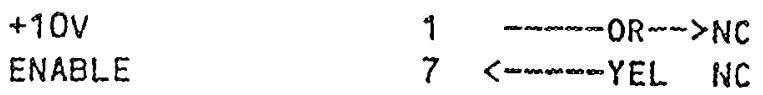

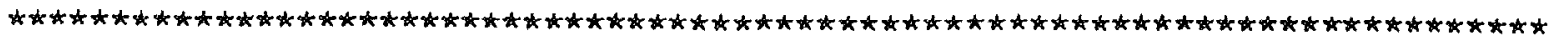

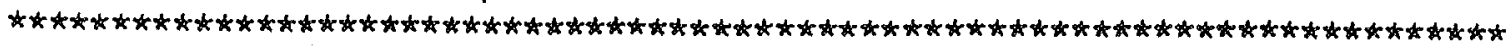

\begin{tabular}{|c|c|c|c|c|}
\hline \multicolumn{2}{|c|}{ 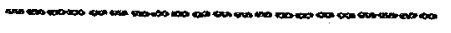 } & \multirow[t]{2}{*}{ 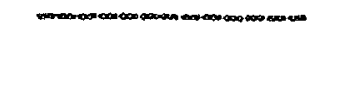 } & \multicolumn{2}{|c|}{ 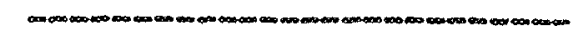 } \\
\hline & & & 9 & PROTECTIVE GROUND \\
\hline SERIAL INPUT & 4 & $<-\infty$ & 2 & $T \times D$ \\
\hline \multirow[t]{4}{*}{ SERIAL OUTPUT } & 3 & - GRNomenom & 3 & $R \times D$ \\
\hline & & $\mathrm{HC}<-\infty$ & 4 & REQUEST TO SEND \\
\hline & & $N C \quad \infty$ & 5 & CLEAR TO SEND \\
\hline & & $-\infty-\infty$ & 6 & DATA SET READY \\
\hline \multirow[t]{2}{*}{ GROUND } & 2 & $\langle-m-m B L K-\infty-m\rangle$ & 7 & GROUND \\
\hline & & NC $<\operatorname{sen}-\infty$ & 20 & DATA TERHINRL READY \\
\hline$+90 v$ & 1 & $\infty N C$ & & . \\
\hline ENABLE & 7 & $<-$ YEL $\quad$ NC & & \\
\hline
\end{tabular}

CABLE, IBM PC ASYNC COMM ADAPTER, 300 BAUD

DR503 cONN. CABLE RS232 cONN. DP25S 